\title{
The impact of resolution on the
} adjustment and decadal variability of the Atlantic Meridional Overturning Circulation in a coupled climate model

Article

Accepted Version

Paper

Hodson, D. L. R. and Sutton, R. T. (2012) The impact of resolution on the adjustment and decadal variability of the Atlantic Meridional Overturning Circulation in a coupled climate model. Climate Dynamics, 39 (12). pp. 3057-3073. ISSN 1432-0894 doi: https://doi.org/10.1007/s00382-0121309-0 Available at https://centaur.reading.ac.uk/26330/

It is advisable to refer to the publisher's version if you intend to cite from the work. See Guidance on citing.

To link to this article DOI: http://dx.doi.org/10.1007/s00382-012-1309-0

Publisher: Springer

Publisher statement: The original publication is available at www.springerlink.com

All outputs in CentAUR are protected by Intellectual Property Rights law, including copyright law. Copyright and IPR is retained by the creators or other copyright holders. Terms and conditions for use of this material are defined in the End User Agreement. 


\section{CentAUR}

Central Archive at the University of Reading

Reading's research outputs online 


\title{
The impact of resolution on the adjustment and decadal variability of the Atlantic Meridional Overturning Circulation in a coupled climate model
}

\author{
4 Daniel L.R. Hodson · Rowan T. Sutton.
}

6 Received: date / Accepted: date

\begin{abstract}
Variations in the Atlantic Meridional Overturning Circulation (MOC) exert an important influence on climate, particularly on decadal time scales. Simulation of the MOC in coupled climate models is compromised, to a degree that is unknown, by their lack of fidelity in resolving some of the key processes involved. There is an overarching need to increase the resolution and fidelity of climate models, but also to assess how increases in resolution influence the simulation of key phenomena such as the MOC.
\end{abstract}

In this study we investigate the impact of significantly increasing the (ocean and atmosphere) resolution of a coupled climate model on the simulation of MOC variability by comparing high and low resolution versions of the same model. In both versions, decadal variability of the MOC is closely linked to density anomalies that propagate from the Labrador Sea southward along the deep western boundary. We demonstrate that the MOC adjustment proceeds more rapidly in the higher resolution model due the increased speed of western boundary waves. However, the response of the Atlantic Sea Surface Temperatures (SSTs) to MOC variations is relatively robust - in pattern if not in magnitude - across the two resolutions. The MOC also excites a coupled ocean-atmosphere response in the tropical Atlantic in both model versions. In the higher resolution model, but not the lower resolution model, there is evidence of a significant response in the extratropical atmosphere over the North Atlantic 6 years after a maximum in the MOC. In both models there is evidence of a weak negative feedback on deep density anomalies in the Labrador Sea, and hence on the MOC (with a time scale of approximately ten years). Our results highlight the need for further work to understand the decadal variability of the MOC and its simulation in climate models.

8 Keywords Atlantic $\cdot$ MOC $\cdot$ Decadal

D.L.R. Hodson

NCAS-Climate, Department of Meteorology

University of Reading, Earley Gate, PO Box 243

Reading, RG6 6BB, UK

Tel.: +44 1183787901

E-mail: d.1.r.hodson@reading.ac.uk 


\section{Introduction}

The Atlantic Meridional Overturning Circulation (MOC) is responsible for a significant fraction of the meridional heat transport from the tropics to higher latitudes ( $\sim 1 P W$ at $26 \mathrm{~N}$; Biastoch et al (2008), Wunsch and Heimbach (2006), Trenberth and Caron (2001)). Studies suggest that the variability in this transport modulates climate, particularly at northern latitudes (e.g. Vellinga et al (2002), Broecker et al (1992)). Although observational estimates of the time mean MOC have been made (Wunsch and Heimbach (2006)), knowledge of its time variations has been hampered by a lack of extended records of subsurface data. Continual monitoring of MOC variability is now underway (Bryden et al (2009), Hirschi et al (2003)), but it will be some decades before enough data is available to infer directly from observations the role of MOC variations in modulating climate.

Numerical climate models provide an important alternative source of information for assessing the nature and potential climate impacts of MOC variability. Climate models suggest that MOC variations have substantial impacts on climate. For example, northern latitudes cool by $\sim 2 \mathrm{~K}$ following a suppression of the MOC (Vellinga et al (2002), Smith and Gregory (2009)), and MOC variations lead to variations in North and South Atlantic Sea Surface Temperatures (SSTs) (Knight et al (2005)). These SST variations can be linked in turn to changes in the seasonal position of the ITCZ, and hence Sahel and South American rainfall (Knight et al (2006), Hodson et al (2009)), in surface air temperatures (Knight et al (2006), Sutton and Hodson (2005)), and in a number of factors controlling Atlantic hurricane genesis in models (Knight et al (2006), Sutton and Hodson (2007), Goldenberg et al (2001)). Models also show that variability in the MOC can arise on timescales ranging from days to centuries (e.g. Knight et al (2005), Fanning and Weaver (1998), Dong and Sutton (2005)). The longer timescales are set by oceanic adjustment processes, which are slow compared to those of the atmosphere. Such long adjustment timescales suggest the potential to predict the MOC and its impacts (e.g. Hawkins and Sutton (2008)); consequently, understanding the decadal variability of the MOC is a key issue for ongoing efforts in Decadal Climate Prediction (Smith et al (2007), Keenlyside et al (2008), Pohlmann et al (2009)).

One of the challenges for understanding decadal variability of the MOC is that the magnitude and dominant time scale of MOC variability has been found to vary substantially between models. These differences arise because of differences in model formulation, but the exact causes can be hard to pinpoint because of the large range of processes involved. A related issue is the modest spatial resolution of current coupled models (typically $\sim 1$ degree in the ocean, and a few degrees in the atmosphere). At such resolutions some of the key processes that are known to influence MOC variability are poorly, or very poorly, resolved. This weakness inevitably calls into question the relevance of the model results to understanding MOC variability in the real world. Indeed, there is a widespread recognition of the need to increase the resolution of climate models, in order to improve the fidelity with which they simulate the numerous processes that influence climate and climate variability (Shaffrey et al (2009)).

Motivated by these issues, the goal of this study is to investigate the simulation of MOC variability in two climate models which differ in resolution, in both the ocean and atmosphere. Our aims are to identify the extent to which these models exhibit similar or differing MOC variability, and to seek to understand the reasons for any differences in terms of simulation of the underlying ocean and ocean-atmosphere processes.

There are many reasons to expect that the simulation of MOC variability may be sensitive to resolution. Interannual and lower frequency variability in the MOC arises primarily from two processes: Ekman transport - driven directly by the surface wind stress, and 
geostrophic transport - driven by the West-East pressure gradient across the Atlantic basin (Hirschi and Marotzke (2007), Balan Sarojini et al (2011)). Multiannual MOC variations are primarily geostrophic. A key mechanism involves the formation of density and pressure anomalies on the western boundary of the Sub-polar Gyre, in response to variations in convection (Marshall and Schott (1999), Gerdes and Köberle (1995)). These boundary anomalies excite baroclinic boundary waves that propagate south along the western boundary, along the equator and then north and south along the eastern boundary, radiating westward propagating Rossby waves as they go (Kawase (1987), Johnson and Marshall (2002), Roussenov et al (2008)). This simple picture of ocean adjustment is complicated by the presence of a sloping coastal shelf, and varying degrees of ocean stratification along the boundary, with the consequence that the boundary wave becomes a hybrid between a coastal shelf wave and a boundary Kelvin wave (Gerdes and Köberle (1995), Shaw and Csanady (1983)). This primary rapid ( $\sim$ years) adjustment by propagation of baroclinic waves is followed by second, slower ( $\sim$ decades), phase of adjustment that occurs due to the self advection of the deep density anomaly along the coastal boundary at depth (Gerdes and Köberle (1995)).

The timescale of the primary adjustment, and hence the timescale of the MOC adjustment, depends on the speed of the boundary waves communicating the presence of the adjustment. Studies have shown that the speed of boundary Kelvin waves is sensitive to model resolution, and related aspects of model formulation. For example, for a viscous fluid represented on a Arakawa B-grid, the along-shore phase speed $^{1}$ of a Kelvin wave falls rapidly as grid spacing increases beyond the Rossby radius (Hsieh et al (1983)). When the grid spacing is ten Rossby radii the Kelvin wave phase speed is only $20 \%$ of the expected continuum value (for an extensive discussion see Hsieh et al (1983)). Many modern coupled models, including the two examined in this study, use an Arakawa B-grid in their ocean component. In addition, the propagation of boundary waves is sensitive to lateral viscosity. Increased values of viscosity reduce the along-shore phase speed of coastal Kelvin waves (Davey et al (1983)). In numerical models values are often used that are larger than observed for reasons of numerical stability (Jochum et al (2008)). A third numerical factor is the orientation of the coastal boundary relative to the ocean grid: the along-shore Kelvin wave speed falls as the angle of the coastline to the underlying grid increases (Schwab (1998)).

The importance of resolution for simulation of MOC variability in climate models was underlined by Döscher et al (1994), who demonstrated - using an ocean model - that the time taken for coastal boundary waves to travel from high latitudes to the equator was dramatically reduced as resolution was increased. Several other ocean model studies have highlighted similar issues (Hsieh et al (1983), Beckmann et al (1994), Böning et al (1996), Getzlaff et al (2005), Hirschi and Stocker (2002), Johnson and Marshall (2002)). However, as MOC variability is ultimately driven by atmospheric processes, and variations in the MOC can influence the atmosphere (e.g. Knight et al (2005)), the potential exists for coupled feedbacks (e.g. Vellinga and Wu (2004)). Hence a complete understanding of MOC variability can only be arrived at by considering the coupled atmosphere-ocean system. Studies which examine the impact of resolution in a coupled system are sparse, due to the expense of performing the required coupled model integrations at varying resolutions. The study by Fanning and Weaver (1998) addressed this issue using an ocean model coupled to a simple $2 \mathrm{~d}$ model of the atmosphere, and concluded that the ocean resolution was a key factor in the generation of decadal scale MOC variability. However, a fuller assessment of the role of coupled feedbacks requires a $3 \mathrm{~d}$ model of the atmosphere.

\footnotetext{
1 and hence group speed, since Kelvin waves are non-dispersive.
} 
In this paper we examine the impact of resolution on the simulation of MOC variability in a coupled climate model. The structure of the paper is as follows. In section 2 we present the models and integrations used for the study. In section 3, we present an analysis of the MOC variability and related climate signals found in the models. A Summary and Conclusions are presented in section 4.

\section{Models and Experiments}

\subsection{Models}

Two Coupled General Circulation Models (CGCMs) were used in this study: HadGEM1.2 and HiGEM1.2. HadGEM1.2 (Johns et al (2006)) is the most recent version of the UK Hadley Centre global coupled general circulation climate model. The atmosphere component has a resolution of $1.25^{\circ}$ latitude by $1.875^{\circ}$ longitude with 38 layers in the vertical. The ocean component, based on the Bryan-Cox code (Bryan (1969), Cox (1984)), uses a latitude-longitude Arakawa-B grid with a zonal resolution of $1^{\circ}$ and a meridional resolution of $1^{\circ}$ between the poles and $30^{\circ}$ latitude, increasing smoothly to $1 / 3^{\circ}$ at the equator. It has 40 unevenly spaced levels in the vertical.

HiGEM1.2 (Shaffrey et al (2009)) is a version of HadGEM1.2 with increased horizontal resolution in both the ocean and the atmosphere. The horizontal resolution has been increased to $0.83^{\circ}$ latitude $\mathrm{x} 1.25^{\circ}$ longitude in the atmosphere and to $1 / 3^{\circ} \mathrm{x} 1 / 3^{\circ}$ in the ocean. The vertical resolution is unchanged in both the atmosphere and ocean components. Small changes are made to some of the parameterizations in the atmosphere to improve model stability but otherwise the HiGEM1.2 atmosphere is identical to that of HadGEM1.2, aside from the change in resolution. The ocean component in HiGEM1.2 is also similarly identical to HadGEM1.2 except that, due to the increased resolution, the Gent-McWilliams (GM - Gent and Mcwilliams (1990)) adiabatic mixing scheme used in HadGEM1.2 is switched off. The higher horizontal resolution of HiGEM permits partial representation of ocean eddies. Tests showed that the inclusion of the GM scheme in HiGEM caused low eddy variability and erosion of fronts. An adiabatic biharmonic scheme is used to reduce tracer field noise. These choices hence preserve ocean features resolvable by the improved resolution. A greater discussion of this and other model differences can be found in Shaffrey et al (2009).

\subsection{Experiments}

100 year control integrations were performed with both HadGEM1.2 and HiGEM1.2. The ocean initial conditions were formed using September potential temperatures and salinities from the $1 / 4^{\circ}$ World Ocean Atlas 2001 (Conkright et al (2002)), with initial velocities set to zero (ocean at rest). Greenhouse gas levels were constant throughout the integrations and identical between the models. Both models reproduce realistic global climates, although there are significant biases (Shaffrey et al (2009)). The climatologies of HiGEM1.2 and HadGEM1.2 control runs are similar, but there are differences, notably HadGEM1.2 SSTs are generally cooler than HiGEM1.2 across the globe. However, oceanic northward heat transports in both models are broadly consistent with the observational estimates. For more details see Shaffrey et al (2009). 


\section{Adjustment and variability of the Atlantic Meridional Overturning Circulation}

In this section we first examine and contrast basic properties of the mean state and variability of the Atlantic Meridional Overturning Circulation in HiGEM1.2 and HadGEM1.2. We then proceed to examine the drivers and time evolution of the MOC, and its interactions with the atmosphere, in detail.

The mean MOCs in HiGEM1.2 and HadGEM1.2 are similar in structure and magnitude (Figures 1a and b). The overturning cell in HadGEM1.2 is somewhat stronger and the Antarctic Bottom Water (AABW) cell somewhat weaker than HiGEM1.2, although these differences may not be significant compared to year-to-year variability. Both models display an initial very rapid ( $\sim 1$ year) reduction in the MOC (HadGEM1.2: 5 Sv, HiGEM1.2: $10 \mathrm{~Sv}$ ), probably in response to unbalanced initialization, followed by a slower spin-up readjustment over at least the first 30 years (Figures 1c and d). After this period, there is a considerable amount of multi-year variability (Figure 1c). Both models have a mean overturning (years 31:100, at 26.7N) (HiGEM1.2: 17.8 Sv, HadGEM1.2: 19.6 Sv) in line with the recent observational estimate of $18.7 \pm 5.6 \mathrm{~Sv}$ (Cunningham et al (2007)).

Figures $1 \mathrm{c}$ and d show that the overturning at $40 \mathrm{~N}$ and $26.7 \mathrm{~N}$ (the latitude of the overturning estimate presented in Cunningham et al (2007)) is generally consistent across latitudes over time within a given model. After the initial 30 year adjustment, there is coherence in the overturning between latitudes on decadal timescales (Figure 2) - as seen in other studies (e.g Balan Sarojini et al (2011)). The tilted contours in both models suggest that changes in the overturning take some time to propagate southwards from their northern source, in a similar manner as seen by Getzlaff et al (2005). There is a possibility that the amplitude of the southward propagating signal is more damped in HadGEM1.2 than HiGEM1.2. The larger amplitude decadal variations in the over-turning are generally found north of $30 \mathrm{~N}$. We now concentrate our analysis on the drivers and impacts of these larger variations by focusing on variations in the MOC at $40 \mathrm{~N}$, the approximate latitude of the maximum meridional stream function in both models (Fig. 1).

Interannual-to-decadal variability in the MOC is substantially driven by dense water anomalies that originate from deep-convection regions in the Labrador and GIN seas (Frankignoul et al (2009), Eden and Willebrand (2001a), Biastoch et al (2008)). Intense surface cooling creates dense surface water which sinks through the less-dense sub-layer, leading to a downward mass flux that drives the overturning. Deep mixed layer depths are a signature of deep convection. Peak (March) mixed layer depths in HiGEM1.2 occur principally over the Labrador Sea $(50 \mathrm{~W}, 55 \mathrm{~N})$ and the northern GIN seas (Figure 3a). Convection sites are similar in HadGEM1.2 : the Labrador Sea and the northern GIN seas (Figure 3b). However mixed layer depths are considerably deeper off the coast of Norway and between Scotland and Iceland than are seen in climatological estimates (de Boyer Montégut (2004)). Despite such differences in the March mean mixed layer depth, the patterns of March variability are more consistent between the models (Figures $3 \mathrm{c}$ and d) being mostly confined to convection sites in the Labrador Sea and the Northern GIN seas. This suggests that, although there are differences in the mean convection, the magnitude of the variability - ultimately the driver for MOC variability - is consistent between the models. Both models have distinct convection sites in the Labrador and GIN seas but comparatively little convection in the Irminger sea. Climate models disagree on the relative importance of these sites in driving the overturning (Frankignoul et al (2009), Eden and Willebrand (2001a) ).

The processes by which dense water anomalies generated by deep convection are communicated to the wider Atlantic Ocean are complex and not fully understood (Palter et al (2008)). Partly this occurs via interior ocean pathways (Bower et al (2009)), and partly 
through the propagation of density signals along the western boundary (e.g. Gerdes and Köberle (1995)). The latter signals are particularly important for the MOC because they project directly onto the cross-basin zonal density contrast that controls the geostrophic northward flow.

We now examine the propagation of density anomalies that exit the Labrador Sea along the Deep Western Boundary. Figure 4a shows HiGEM1.2 annual mean depth integrated (1500:3000m) ocean density correlated with a point on the western boundary (point B, at $40 \mathrm{~N}$ ). There is a very narrow band of high correlations (corr $>0.7$ ) along the western boundary of the North Atlantic, extending from the southern tip of Greenland to the northern coast of South America. Such a high correlation over an extended region implies a rapidly propagating signal connecting distant points and this is most likely communicated by a rapid boundary wave response. This boundary wave response is likely to be a mixed KelvinShelf wave (Gerdes and Köberle (1995)). There are widespread correlations throughout the Labrador sea, demonstrating that the Labrador sea is a major source of density variations on the western boundary at depth in HiGEM1.2.

Similar high correlations along the western boundary are also found in HadGEM1.2 (Figure 4d), although the correlations in the Labrador sea are much weaker. This difference reflects a difference between the models in the timescales for density anomalies to propagate out of the Labrador basin (see Figures 5 and 6, to be discussed shortly).

Density anomalies at the western boundary cause changes in pressure, and hence changes in the west-east pressure gradient which drive changes in the MOC. We can examine this relation between the overturning and the ocean density on the boundaries by following Hirschi and Marotzke (2007). Thermal wind balance states that:

$$
f \frac{\partial v}{\partial z}=-\frac{g}{\rho^{*}} \frac{\partial \rho}{\partial x}
$$

where $v(x, y, z, t)$ is the meridional ocean velocity, $\rho$ ocean density, $\rho^{*}$ a reference density, $f$ the Coriolis parameter and $g$ the acceleration due to gravity. Integrating across the ocean basin, from west $\left(x_{w}\right)$ to east $\left(x_{e}\right)$ and over $z$ from the ocean floor $(z=D)$ up to $z$ gives:

$$
\int_{x_{w}}^{x_{e}}(v(z)-v(D)) d x=-\frac{g}{f \rho^{*}} \int_{D}^{z}\left(\rho_{e}-\rho_{w}\right) d z
$$

where $\rho_{e}\left(\rho_{w}\right)$ is the density on the Eastern (Western) ocean boundary. Integrating over $z$ again:

$$
\int_{D}^{z} \int_{x_{w}}^{x_{e}}(v(z)-v(D)) d x d z=-\frac{g}{f \rho^{*}} \int_{D}^{z} \int_{D}^{z}\left(\rho_{e}-\rho_{w}\right) d z d z
$$

We now follow Hirschi and Marotzke (2007) and assume that the bottom ocean velocities are zero $(v(D)=0)$. The left hand side of (3) is hence the volume flux below a depth $z$, i.e. the stream function $\Psi(z)$ or overturning. Hence the volume flux is proportional to the double integral of the boundary density difference. For the remainder of this paper we make two further assumptions. i) Variations over time in the density contrast on the right hand side of (3) are dominated by $\rho_{w}$ - this is likely to be true because of greater density variations along the western boundary that are not present on the eastern boundary. ii) Variations in the volume flux below $1000 \mathrm{~m}$ are dominated by the region between $1500 \mathrm{~m}$ and $3000 \mathrm{~m}$. This region captures the depths of maximum southward flow and excludes variations in the Antarctic Bottom Water (Figure 1). Hence (3) can be reduced to:

$$
\Psi(1000) \approx \frac{g}{f \rho^{*}} \int_{3000}^{1500} \int\left(\rho_{w}\right) d^{2} z
$$


Figure $4 \mathrm{~b}$ demonstrates that in HiGEM1.2 (at 40N) variations in (4) are indeed well correlated with the overturning at $40 \mathrm{~N}$ (corr $=0.6$ ). Interestingly, the overturning is almost identically correlated with the single integral of the density on the boundary (corr $=0.57$ ). That is:

$$
\operatorname{MOC}^{*} \propto \int_{3000}^{1500}\left(\rho_{w}\right) d z
$$

This relationship appears to hold in both HiGEM1.2 and HadGEM1.2 (figure 4). MOC* and the overturning are well correlated at $40 \mathrm{~N}$ but they are less well correlated further south at $27 \mathrm{~N}$, the latitude of the RAPID array (Figure $4 \mathrm{c}$, corr $=0.40$ ). This may be due to increased influence of wind driven (Ekman) transport variability at this latitude, or the failure of one of our assumptions in the derivation of (4). In HadGEM1.2, The correlation between the boundary density and the MOC is greater than HiGEM1.2 (Figure 4e and f), most likely due to the presence of the larger amplitude decadal signal in HadGEM1.2. The correlations between the boundary density and the MOC are similarly stronger at $40 \mathrm{~N}$ (corr $=0.80$ ) than 26.7N (corr $=0.38)$ in HadGEM1.2.

It is apparent from Figure 4 that the correlation between $\mathrm{MOC}^{*}$ and the actual overturning is particularly high on decadal timescales. This is partly because MOC* filters out $^{*}$ the Ekman contribution to MOC variability that is large on interannual (and shorter) time scales, but is of relatively little interest from a climatic point of view. For this reason, for the remainder of this paper we will use $\mathrm{MOC}^{*}$ at $40 \mathrm{~N}$, as our measure of MOC variability. Hence we are focusing on that component of the MOC variability that is directly related to variations in the density on the deep western boundary.

\subsection{Ocean Adjustment}

We now examine the temporal evolution of the boundary density anomaly that controls the MOC adjustment. Figure 5 shows the 1500-3000m integrated density lag-regressed onto MOC* $^{*}$ at 40N in HiGEM1.2 . Positive density anomalies are seen in the Labrador Sea four years prior to a maximum in MOC* (panel a). Subsequent lags show a boundary density signal propagating out of the Labrador Sea, along the western boundary (panels b, c, d). When this signal reaches the equator it triggers a tropical response that is consistent with theoretical expectations and other studies (e.g. Johnson and Marshall (2002)). The tropical response is governed by the excitation of an eastward propagating equatorial Kelvin wave, which subsequently excites coastal Kelvin waves on the eastern boundary, which then radiate westward propagating Rossby waves. This signal is weak $(p<0.10)$, but clear at Lags 0 and 2 . These signals subsequently decay (panels e, f). In addition to the western boundary signal, density anomalies are seen to propagate southward into the interior of the basin, in a manner consistent with recent observations (Bower et al (2009)) (Figure 5d, e, f). Lastly, there is an interesting hint in panel $\mathrm{f}$ of negative density anomalies around the boundary of the Labrador Sea. These negative anomalies appear 6 years after a maximum in the MOC* and could suggest a negative feedback on MOC variations.

A similar picture emerges for HadGEM1.2 (Figure 6). Density anomalies propagate out of the Labrador basin and around the western boundary (panels a-d) - although the boundary density signal is less tightly confined to the western boundary than the HiGEM1.2 signal and finally across the equator (at Lag 2), in the manner described above.

The equatorial Kelvin-wave response occurs somewhat earlier in HiGEM1.2 (Lag 0 years) than HadGEM1.2 (Lag 2 years). This suggests that density anomalies may take longer to propagate along the western boundary to the equator in HadGEM1.2 than in HiGEM1.2 . 
As noted in the introduction, it is well-known that boundary wave propagation speeds on Arakawa-B grids are sensitive to model resolution (Hsieh et al (1983)). Both oceans models in HiGEM1.2 and HadGEM1.2 are discretized on Arakawa-B grids (Johns et al (2006), Shaffrey et al (2009)) so it is likely that the different timescales for propagation of the boundary density waves between the models can be attributed to the differences in ocean model resolution. Indeed examining the variation of the Rossby radius of deformation within the Atlantic (Chelton et al (1998)) reveals that boundary density waves are not well resolved in HadGEM1.2 north of 10N whereas they are resolved in HiGEM1.2 south of around 30N. Hence we expect that the propagation speed of boundary waves in HadGEM1.2 will differ from that in HiGEM1.2 between $10 \mathrm{~N}$ and $30 \mathrm{~N}$.

In other respects, the ocean evolution in HadGEM1.2 is similar to that in HiGEM1.2 . HadGEM1.2 displays propagation of Labrador Sea density anomalies into the basin interior, and also a negative density anomaly in the Labrador Sea at lag 6 (Figure 6f).

\subsection{Atmosphere-Ocean Interactions}

We now turn our attention to the interaction of MOC variability with the overlying atmosphere. Figures 7 and 8 show lagged regressions of Mean Sea Level Pressure (MSLP) onto $\mathrm{MOC}^{*}$ at $40 \mathrm{~N}$ for the two models. We focus first on negative lags, which may provide evidence of the atmospheric forcing of MOC variability. In HiGEM1.2 strong negative MSLP anomalies are found over Greenland 2-4 years before a maximum in MOC* (Figure 7a and b). The pressure gradients associated with these anomalies will induce anomalous southward (northerly) winds over the Labrador Sea, advecting cold air over the region, resulting in intense cooling. This cooling is clearly seen in the surface heat fluxes over the Labrador Sea at these lags (not shown). Hence in HiGEM1.2 dense Labrador Sea water, generated by wind-driven surface cooling, subsequently induces changes in the MOC. This is consistent with many previous studies (Dickson et al (1996), Curry et al (1998), Eden and Willebrand (2001a), Bentsen et al (2004), Guemas and Salas-Mélia (2008)).

In contrast to HiGEM1.2, in HadGEM1.2 there is little evidence of significant and coherent MSLP anomalies over the North Atlantic at negative lags (Figures 8a, b). (Such signals are also not found at more negative lags (not shown)). This suggests that the large amplitude decadal fluctuations in the MOC* in HadGEM1.2 (figures 4e and f) are not directly forced by the atmosphere over the North Atlantic. They may, for example, originate from ocean density anomalies propagating out of the Arctic.

Next we consider positive lags, which may provide evidence of an atmospheric response to MOC variability. To aid the interpretation of these signals we also need to examine the regression patterns for sea surface temperature (SST) on MOC* (Figure 9). The SST pattern for HiGEM1.2 at lag 0 (panel a) shows cool (negative) anomalies over the Labrador Sea, as expected in response to the cooling by surface heat fluxes over the preceding years (see e.g. Eden and Willebrand (2001a) etc). Warm (positive) anomalies are also seen over the Gulf Stream extension and North Atlantic Current region. Over subsequent years (panels $\mathrm{b}$ and c), this warm anomaly appears to propagate northwards into the eastern part of the sub-polar gyre, whilst the cool anomalies over the western sub-polar gyre decay. By lag 6 , warm anomalies cover the sub-polar gyre and are also linked along the eastern boundary to a warm anomaly in the tropical North Atlantic. A small cool anomaly is found in the region of the Gulf Stream extension. Similar negative anomalies have been linked to a southward displacement of the Gulf Stream front related to variability in the MOC (Zhang (2008)). 
The evolution of MSLP at positive lags in HiGEM1.2 (Figure 7e,f) shows initially the appearance of a low pressure anomaly over the tropical Atlantic, and subsequently - at lag 6 - a dipolar pattern with a high pressure anomaly centred over Greenland and a low pressure anomaly over the mid-latitude North Atlantic. This MSLP pattern is associated with a weakening of the westerlies that are closely linked with the North Atlantic storm track. Inspection of the SST pattern at this time (Figure 9c) shows a weakening of the meridional SST gradient east of Newfoundland. Such a weakening of the SST gradient would be expected to weaken the storm track, and may provide a mechanism for the excitation of a large-scale atmospheric response, as suggested by Figure 7f. Additionally, this may also be a remote response to the developing Tropical Atlantic SST warm anomaly (see e.g. Terray and Cassou (2002), Dréevillon et al (2003) and Cassou et al (2004)).

The evolution of SST in HadGEM1.2 (Figure 9d-f) shows some similar features to HiGEM1.2 but the anomalies are of greater magnitude. At lag 0, a warm anomaly is again seen in the region of the North Atlantic Current, and this anomaly subsequently appears to propagate into the sub-polar gyre, concurrent with the development of a linked warm anomaly in the tropical North Atlantic. Significant warm tropical SST anomalies appear earlier in HadGEM and are linked with cool (negative) SST anomalies south of the equator (and hence a cross-equator SST gradient). A (very) small cool SST anomaly is also found at lag 6 in the region of the Gulf Stream extension. The evolution of MSLP (Figure 8d,e,f) shows the development of a low pressure anomaly over the tropical North Atlantic, with peak intensity at lag 4 (when a similar signal was seen in HiGEM1.2). There are no strong anomalies in MSLP over the higher latitude North Atlantic in HadGEM1.2 . Large anomalies are present over the North Pacific but it is unclear whether these are causally linked to the variability in the Atlantic basin.

In both models significant anomalies in both MSLP and SST develop in the tropical North Atlantic. The tropical Atlantic is a region of strong ocean-atmosphere coupling, where - moreover - coupled feedbacks, particularly related to the cross-equator SST gradient, can act to amplify initially small anomalies (e.g. Chang et al (1997), Sutton et al (2000)). There is evidence of these feedbacks operating in both HadGEM1.2 and HiGEM1.2 . Figure 11 shows the surface wind stress and wind speed anomalies at lag 6 in the two models. In both cases there is cross-equator flow, as expected in response to the cross-equator SST gradient. Furthermore, the variations in wind speed magnitude and direction are consistent with turbulent (latent and sensible) surface heat flux anomalies that will act to reinforce the anomalous SSTs both north and south of the equator. Note that there is also an associated northward displacement of the ITCZ (not shown).

An interesting question concerning the tropical response is whether it is linked in any way to the deep density signal propagating along the western boundary (Figure 5 and Figure 6). Examining the vertical structure of temperature anomalies in the tropical North Atlantic at lag 6 (Figure 10a \& b) shows a deep sub-surface negative temperature anomaly in HadGEM1.2 that is related to the high density anomaly seen in Figure $6 f$. A similar but much weaker anomaly can be seen in HiGEM1.2 . In both cases, however, the deep anomalies are much weaker than those near the surface, and show no obvious connection to them. Rather it appears that the near surface anomalies can be more readily understood as a response to the surface wind anomalies (Figure 11). This response involves anomalous turbulent heat fluxes, as previously mentioned, and also - particularly within $\sim 5^{\circ}$ of the Equator - anomalies in Ekman pumping. Figure 11d indicates downward Ekman pumping near the Equator in HadGEM1.2, which acts to deepen the thermocline. This influence explains the presence of a warm temperature anomaly beneath the cool SST anomalies in the tropical South At- 
lantic (Figure 10d) and the warm subsurface temperature anomalies in the tropical North Atlantic (Figure 10c).

Although the upper ocean response appears to be dominated by the influence of the atmosphere, and related coupled feedbacks, it is still possible that the density signals propagating along the western boundary might provide an initial trigger for the development of tropical SST anomalies that subsequently amplify through coupled feedbacks. One way in which this might happen is through a modulation of the North Brazil Current (NBC) (e.g. Zhang et al (2011)) and its subsequent effects on SST. To investigate this question we correlated various indices of the NBC with $\mathrm{MOC}^{*}$. Figure 12 shows results for an NBC index, defined as the meridional northward ocean velocity integrated over the top $100 \mathrm{~m}$ in the ocean and then averaged over the region $(60 \mathrm{~W}: 45 \mathrm{~W}, 2 \mathrm{~N}: 10 \mathrm{~N})$ and then detrended. Whilst the correlations are weak, in the case of HadGEM1.2 significant correlations are found for lags between 0 and 6 years following a maximum in $\mathrm{MOC}^{*}$. This link between a MOC* maximum and an acceleration of the NBC may be mediated by the baroclinic coastal Kelvin waves that follow a $\mathrm{MOC}^{*}$ maximum. It might also be mediated by the wind stress anomalies that develop over the tropical Atlantic (Figure 11) or a number of other mechanisms (see Zhang et al (2011)). However, the fact that the correlation in Fig 12a starts to increase rapidly around 4 years before a maximum in the $\mathrm{MOC}^{*}$ (i.e. Lag -4), before significant wind anomalies have developed, suggests the deep density signal may indeed play a triggering role. This does not provide conclusive evidence of a causal oceanic connection, but does suggest such a connection may exist. In HiGEM1.2, the evidence is weaker.

If the deep density signals do not provide the initial trigger for development of the tropical anomalies, what other mechanisms might? One possibility is an atmospheric teleconnection from the higher latitude North Atlantic. Extratropical forcing of the tropical Atlantic has been demonstrated in several recent modelling studies (Broccoli et al (2006) and Zhang et al (2010), Kang et al (2009)). Another possibility is an oceanic teleconnection via advection of SST anomalies from the Gulf Stream region southward around the subtropical gyre and into the tropics. The pattern of SST anomalies seen in HiGEM1.2 at lag 6 (Figure $9 \mathrm{~b}$ ) is possibly suggestive of this mechanism, but it perhaps unlikely that this is a dominant factor, in view of the tendency for midlatitude SST anomalies to be damped unless maintained by strong circulation anomalies. Also, the timescale of propagation seen appears to be faster than those that could be supported by passive advection by a climatological ocean circulation.

A last point of interest is the hints from Figures 5 and 6 of a negative feedback on deep density in the Labrador Sea, with negative anomalies following positive anomalies by around 10 years in both HiGEM1.2 and HadGEM1.2. The signals are weak and should not be over-interpreted, but the consistency between the models is interesting and could suggest a robust mechanism. What might this mechanism be? A simple possibility is suggested by Figure 9c,f. This figure shows that the appearance of negative density anomalies at depth in the Labrador Sea follows, and coincides with, the warming of SST over the whole subpolar gyre, including the Labrador Sea. This warming will tend to increase stratification and inhibit the tendency of wintertime convection to cool the subsurface ocean. Therefore we tentatively hypothesise that the negative feedback arises from the northward propagation of the warming signal from the North Atlantic Current region into the sub-polar gyre, associated with a peak in the MOC. Note that this evolution is very similar to that which was observed in the real world during the mid-1990s (Robson et al (2011)). 


\section{Summary and Conclusions}

In this paper we have examined the adjustment and decadal variability of the Atlantic Meridional Overturning Circulation (MOC) in two coupled climate models, which differ only in respect of resolution. The two models - HiGEM1.2 (high horizontal resolution) and HadGEM1.2 (standard horizontal resolution) - were integrated using identical initial and boundary conditions. We then examined and compared the evolution of the MOC, and its interactions with the atmosphere, in each model. The major findings are as follows:

- In both HiGEM1.2 and HadGEM1.2, decadal variability of the MOC is very closely tied to variability in density along the deep western boundary of the Atlantic Ocean. Density anomalies formed in the Labrador Sea propagate southwards along the western boundary and into the tropics, consistent with theory and much simpler models (e.g. Johnson and Marshall (2002)). Density anomalies also propagate into the interior of the North Atlantic basin, consistent with observations (Bower et al (2009)).

- In HiGEM1.2, density anomalies in the Labrador Sea appear to be generated in response to atmospheric variations that modulate air-sea fluxes, consistent with many other studies ( e.g. Eden and Willebrand (2001b), Köhl (2005)). Such a link is not seen in HadGEM1.2.

- Both models respond to Labrador Sea density anomalies in a similar way but the time taken for the anomalies to propagate to the equator differs. HadGEM1.2 adjusts more slowly (by 1-2 years) than HiGEM1.2. This difference is attributed to slower western boundary waves in HadGEM1.2, which are expected as a consequence of the lower horizontal resolution (Hsieh et al (1983)).

- Despite this difference in the adjustment timescale of the deep ocean, the North Atlantic SST anomalies that are related to the MOC evolve in a similar manner in the two models. The magnitude of SST anomalies is larger in HadGEM1.2 than in HiGEM1.2, but in both cases warm anomalies are first seen in the region of the Gulf Stream Extension / North Atlantic Current, and subsequently spread throughout the sub polar gyre and also develop in the tropical North Atlantic.

- In both models, the tropical SST anomalies are linked to local MSLP anomalies and grow over several years, likely through coupled ocean-atmosphere feedbacks that involve the cross-equator SST gradient. Wind anomalies are associated with anomalous surface fluxes that influence SST and also, close to the Equator, anomalous Ekman pumping that influences thermocline depth. The initial trigger for the development of a tropical SST and atmosphere response may arise from an atmospheric teleconnection from the North Atlantic. In the case of HadGEM1.2 there is also evidence of a role for an acceleration of the near surface North Brazil Current, possibly linked to the deep density anomaly that propagates southward from the North Atlantic.

- In HiGEM1.2 there is evidence of a significant response in the extratropical atmosphere over the North Atlantic 6 years after a maximum in the MOC. A dipolar pattern of MSLP is related to a weakening of the mid-latitude westerlies that may be a response to a weakening of the meridional SST gradient east of Newfoundland. Such a response is not seen in HadGEM1.2.

- In both models there is evidence of a weak negative feedback on density anomalies in the Labrador Sea, and hence on the MOC. This feedback is related to a warming of the upper sub-polar gyre that increases stratification and is expected to inhibit convection. The time scale for this feedback is approximately 10 years in both models. 
These results suggest that for climate models, at least with those where the ocean is discretized on an Arakawa B grid, the timescale of deep ocean evolution and adjustment is sensitive to resolution. However, the evolution of SST - a key issue from the perspective of decadal forecasting - appears less affected by resolution in terms of timing and pattern (although it is harder to make a firm statement about the magnitude). The response of tropical SST and climate shows important robust features between the two models, but also many detailed differences. Perhaps the most important differences are those seen in the extratropical atmosphere, where the behaviour of the two models appears quite different. Further understanding of these differences will clearly be an important topic for further work.

To end we acknowledge some limitations of our study. Firstly, ideally we would have had available longer model simulations and therefore more realisations of decadal fluctuations. Unfortunately the computation cost of the high resolution model precluded this. Secondly, in discussing our results we have assumed implicitly that all the differences are directly attributable to the differences in resolution. Because some modest re-tuning (e.g. to the ocean mixing schemes) was required, this might not be the case. On the other hand, such secondary changes may be considered part of the change in the model resolution, since no stable model would exist without them.

We have focused in this paper on two models that use an ocean model based on an Arakawa B-grid ocean. Many other ocean models use the Arakawa-C grid discretization. The C-grid is predicted to be less sensitive to resolution in terms of boundary wave speed (Hsieh et al (1983)). Further experiments will be required to assess whether the behaviour of the MOC is indeed less sensitive to horizontal resolution in climate models that employ a C-grid ocean.

It remains the case that the resolution of current climate models places a fundamental limitation on their fidelity. Understanding how increases in resolution influence the simulation of mean climate, climate variability and change is a key challenge on which a great deal of further work is required.

Acknowledgements The Authors would like to thank Len Shaffrey and the HiGEM project for use of the HiGEM and HadGEM data in this study and two anonymous Reviewers for their valuable comments which notably improved the manuscript. This work was funded by the UK National Environment Research Council (NERC) Grant no. NE/F018533/1 and by the NERC NCAS-Climate programme.

\section{References}

Balan Sarojini B, Gregory JM, Tailleux R, Bigg GR, Blaker AT, Cameron D, Edwards NR, Megann AP, Shaffrey LC, Sinha B (2011) High frequency variability of the Atlantic meridional overturning circulation. Ocean Science Discussions 8(1):219-246 doi: doi:10.5194/osd-8-219-2011

Böning CW, Bryan FO, Holland WR, Döscher R (1996) Deep-Water Formation and Meridional Overturning in a High-Resolution Model of the North Atlantic. Journal of Physical Oceanography 26(7):1142-1164, doi:10.1175/15200485(1996)026\%3C1142:DWFAMO\%3E2.0.CO;2

Beckmann A, Böning CW, Köberle C, Willebrand J (1994) Effects of Increased Horizontal Resolution in a Simulation of the North Atlantic Ocean. Journal of Physical Oceanography 24(2):326-344, doi:10.1175/1520-0485(1994)024\%3C0326:EOIHRI\%3E2.0.CO;2 
Bentsen M, Drange H, Furevik T, Zhou T (2004) Simulated variability of the Atlantic meridional overturning circulation. Climate Dynamics 22(6):701-720, doi:10.1007/s00382004-0397-x

Biastoch A, Böning CW, Getzlaff J, Molines JM, Madec G (2008) Causes of InterannualDecadal Variability in the Meridional Overturning Circulation of the Midlatitude North Atlantic Ocean. J Climate 21(24):6599-6615, doi:10.1175/2008JCLI2404.1

Bower AS, Lozier SM, Gary SF, Boning CW (2009) Interior pathways of the North Atlantic meridional overturning circulation. Nature 459(7244):243-247, doi:10.1038/nature07979

de Boyer Montégut C (2004) Mixed layer depth over the global ocean: An examination of profile data and a profile-based climatology. Journal of Geophysical Research 109(C12), doi:10.1029/2004JC002378

Broccoli AJ, Dahl KA, Stouffer RJ (2006) Response of the ITCZ to Northern Hemisphere cooling. Geophysical Research Letters 33(1):L01,702+, doi:10.1029/2005GL024546

Broecker W, Bond G, Klas M, Clark E, McManus J (1992) Origin of the northern Atlantic's Heinrich events. Climate Dynamics 6(3):265-273, doi:10.1007/BF00193540

Bryan K (1969) A numerical method for the study of the circulation of the world ocean. Journal of Computational Physics 4(3):347-376, doi:10.1016/0021-9991(69)90004-7

Bryden HL, Mujahid A, Cunningham SA, Kanzow T (2009) Adjustment of the basin-scale circulation at $26 \mathrm{~N}$ to variations in Gulf Stream, deep western boundary current and Ekman transports as observed by the Rapid array. Ocean Science Discussions 6(1):871-908

Cassou C, et al (2004) Summer sea surface temperature conditions in the north atlantic and their impact upon the atmospheric circulation in early winter. J Climate 17:3349-3363

Chang P, Ji L, Li H (1997) A decadal climate variation in the tropical Atlantic Ocean from thermodynamic air-sea interactions. Nature 385(6616):516-518, doi:10.1038/385516a0

Chelton DB, deSzoeke RA, Schlax MG, El Naggar K, Siwertz N (1998) Geographical Variability of the First Baroclinic Rossby Radius of Deformation. Journal of Physical Oceanography 28(3):433-460, doi:10.1175/15200485(1998)028\%3C0433:GVOTFB\%3E2.0.CO;2

Conkright ME, Locarnini RA, Garcia HE, O’Brien TD, Boyer TP, Stephen C, Antonov JI (2002) World Ocean Atlas 2001: Objective Analyses, Data Statistics, and Figures, CDROM Documentation. National Oceanographic Data Center, Internal Rep (17)

Cox MD (1984) A primitive equation, three dimensional model of the ocean. Tech. rep., GFDL, Princeton, NJ

Cunningham SA, Kanzow T, Rayner D, Baringer MO, Johns WE, Marotzke J, Longworth HR, Grant EM, Hirschi JJM, Beal LM, Meinen CS, Bryden HL (2007) Temporal variability of the atlantic meridional overturning circulation at 26.5 degreesn. Science 317(5840):935-938, doi:10.1126/science.1141304

Curry RG, McCartney MS, Joyce TM (1998) Oceanic transport of subpolar climate signals to mid-depth subtropical waters. Nature 391(6667):575-577, doi:10.1038/35356

Döscher R, Böning CW, Herrmann P (1994) Response of Circulation and Heat Transport in the North Atlantic to Changes in Thermohaline Forcing in Northern Latitudes: A Model Study. Journal of Physical Oceanography 24(11):2306-2320, doi:10.1175/15200485(1994)024\%3C2306:ROCAHT\%3E2.0.CO;2

Davey MK, Hsieh WW, Wajsowicz RC (1983) The Free Kelvin Wave with Lateral and Vertical Viscosity. Journal of Physical Oceanography 13(12):2182-2191, doi:10.1175/15200485(1983)013\%3C2182:TFKWWL\%3E2.0.CO;2

Dickson R, Lazier J, Meincke J, Rhines P, Swift J (1996) Long-term coordinated changes in the convective activity of the North Atlantic. Progress In Oceanography 38(3):241-295, 
doi:10.1016/S0079-6611(97)00002-5

Dong B, Sutton RT (2005) Mechanism of Interdecadal Thermohaline Circulation Variability in a Coupled Ocean\&\#8211;Atmosphere GCM. Journal of Climate 18(8):1117-1135, doi: 10.1175/JCLI3328.1

Dréevillon M, Cassou C, Terray L (2003) Model study of the North Atlantic region atmospheric response to autumn tropical Atlantic sea-surface-temperature anomalies. QJR Meteorol Soc 129(593):2591-2611, doi:10.1256/qj.02.17

Eden C, Willebrand J (2001a) Mechanism of Interannual to Decadal Variability of the North Atlantic Circulation. J Climate 14(10):2266-2280, doi:10.1175/15200442(2001)014\%3C2266:MOITDV\%3E2.0.CO;2

Eden C, Willebrand J (2001b) Mechanism of interannual to decadal variability of the north atlantic circulation. J Climate 14(10):2266-2280

Fanning AF, Weaver AJ (1998) Thermohaline Variability: The Effects of Horizontal Resolution and Diffusion. Journal of Climate 11(4):709-715, doi:10.1175/15200442(1998)011\%3C0709:TVTEOH\%3E2.0.CO;2

Frankignoul C, Deshayes J, Curry R (2009) The role of salinity in the decadal variability of the North Atlantic meridional overturning circulation. Climate Dynamics 33(6):777-793, doi:10.1007/s00382-008-0523-2

Gent PR, Mcwilliams JC (1990) Isopycnal Mixing in Ocean Circulation Models. Journal of Physical Oceanography 20(1):150-155, doi:10.1175/15200485(1990)020\%3C0150:IMIOCM\%3E2.0.CO;2

Gerdes R, Köberle C (1995) On the Influence of DSOW in a Numerical Model of the North Atlantic General Circulation. J Phys Oceanogr 25(11):2624-2642, doi:10.1175/15200485(1995)025\%3C2624:OTIODI\%3E2.0.CO;2

Getzlaff J, Böning CW, Eden C, Biastoch A (2005) Signal propagation related to the North Atlantic overturning. Geophysical Research Letters 21

Goldenberg SB, Landsea CW, Mestas-Nuñez AM, Gray WM (2001) The Recent Increase in Atlantic Hurricane Activity: Causes and Implications. Science 293(5529):474-479, doi: 10.1126/science. 1060040

Guemas V, Salas-Mélia D (2008) Simulation of the Atlantic meridional overturning circulation in an atmosphereocean global coupled model. Part I: a mechanism governing the variability of ocean convection in a preindustrial experiment. Climate Dynamics 31(1):29-48, doi:10.1007/s00382-007-0336-8

Hawkins E, Sutton R (2008) Potential predictability of rapid changes in the Atlantic meridional overturning circulation. Geophysical Research Letters 35(11):L11,603+, doi: 10.1029/2008GL034059

Hirschi J, Marotzke J (2007) Reconstructing the Meridional Overturning Circulation from Boundary Densities and the Zonal Wind Stress. Journal of Physical Oceanography 37(3):743-763, doi:10.1175/JPO3019.1

Hirschi J, Stocker TF (2002) Rapid changes of the oceanic circulation in a hierarchy of ocean models. Tellus A 54(3):273-287, doi:10.1034/j.1600-0870.2002.00323.x

Hirschi J, Baehr J, Marotzke J, Stark J, Cunningham S, Beismann JO (2003) A monitoring design for the Atlantic meridional overturning circulation. Geophysical Research Letters 30(7):1413+, doi:10.1029/2002GL016776

Hodson DLR, Sutton RT, Cassou C, Keenlyside N, Okumura Y, Zhou T (2009) Climate impacts of recent multidecadal changes in Atlantic Ocean Sea Surface Temperature: a multimodel comparison. Climate Dynamics doi:10.1007/s00382-009-0571-2

Hsieh WW, Davey MK, Wajsowicz RC (1983) The Free Kelvin Wave in FiniteDifference Numerical Models. Journal of Physical Oceanography 13(8):1383-1397, doi: 
10.1175/1520-0485(1983)013\%3C1383:TFKWIF\%3E2.0.CO;2

Jochum M, Danabasoglu G, Holland M, Kwon YO, Large WG (2008) Ocean viscosity and climate. Journal of Geophysical Research 113(C6):C06,017+, doi: 10.1029/2007JC004515

Johns TC, Durman CF, Banks HT, Roberts MJ, McLaren AJ, Ridley JK, Senior CA, Williams KD, Jones A, Rickard GJ, Cusack S, Ingram WJ, Crucifix M, Sexton DMH, Joshi MM, Dong BW, Spencer H, Hill RSR, Gregory JM, Keen AB, Pardaens AK, Lowe JA, Bodas-Salcedo A, Stark S, Searl Y (2006) The New Hadley Centre Climate Model (HadGEM1): Evaluation of Coupled Simulations. Journal of Climate 19(7):1327-1353, doi:10.1175/JCLI3712.1

Johnson HL, Marshall DP (2002) A Theory for the Surface Atlantic Response to Thermohaline Variability. Journal of Physical Oceanography 32(4):1121-1132, doi:10.1175/15200485(2002)032\%3C1121:ATFTSA\%3E2.0.CO;2

Köhl A (2005) Anomalies of Meridional Overturning: Mechanisms in the North Atlantic. Journal of Physical Oceanography 35(8):1455-1472, doi:10.1175/JPO2767.1

Kang SM, Frierson DMW, Held IM (2009) The Tropical Response to Extratropical Thermal Forcing in an Idealized GCM: The Importance of Radiative Feedbacks and Convective Parameterization. Journal of the Atmospheric Sciences 66:2812-2827

Kawase M (1987) Establishment of Deep Ocean Circulation Driven by Deep-Water Production. Journal of Physical Oceanography 17(12):2294-2317, doi:10.1175/15200485(1987)017\%3C2294:EODOCD\%3E2.0.CO;2

Keenlyside NS, Latif M, Jungclaus J, Kornblueh L, Roeckner E (2008) Advancing decadalscale climate prediction in the North Atlantic sector. Nature 453(7191):84-88, doi: 10.1038/nature06921

Knight JR, Allan RJ, Folland CK, Vellinga M, Mann ME (2005) A signature of persistent natural thermohaline circulation cycles in observed climate. Geophysical Research Letters 32(20):L20,708+, doi:10.1029/2005GL024233

Knight JR, Folland CK, Scaife AA (2006) Climate impacts of the Atlantic Multidecadal Oscillation. Geophysical Research Letters 33(17):L17,706+, doi:10.1029/2006GL026242

Marshall J, Schott F (1999) Open-ocean convection: Observations, theory, and models. Reviews of Geophysics 37(1):null-64, doi:10.1029/98RG02739

Palter JB, Lozier MS, Lavender KL (2008) How Does Labrador Sea Water Enter the Deep Western Boundary Current? J Phys Oceanogr 38(5):968-983, doi: 10.1175/2007JPO3807.1

Pohlmann H, Jungclaus JH, Köhl A, Stammer D, Marotzke J (2009) Initializing Decadal Climate Predictions with the GECCO Oceanic Synthesis: Effects on the North Atlantic. J Climate 22(14):3926-3938, doi:10.1175/2009JCLI2535.1

Robson J, Sutton R, Lohmann K, Smith D, Palmer M (2011) Causes of the rapid warming of the north atlantic ocean in the mid 1990s. J Climate

Roussenov VM, Williams RG, Hughes CW, Bingham RJ (2008) Boundary wave communication of bottom pressure and overturning changes for the North Atlantic. Journal of Geophysical Research 113:C08,042+, doi:10.1029/2007JC004501

Schwab D (1998) Propagation of Kelvin waves along irregular coastlines in finitedifference models. Advances in Water Resources 22(3):239-245, doi:10.1016/S03091708(98)00015-3

Shaffrey LC, Stevens I, Norton WA, Roberts MJ, Vidale PL, Harle JD, Jrrar A, Stevens DP, Woodage MJ, Demory ME, Donners J, Clark DB, Clayton A, Cole JW, Wilson SS, Connolley WM, Davies TM, Iwi AM, Johns TC, King JC, New AL, Slingo JM, Slingo A, Steenman-Clark L, Martin GM (2009) U.K. HiGEM: The New U.K. High- 
Resolution Global Environment ModelModel Description and Basic Evaluation. J Climate 22(8):1861-1896, doi:10.1175/2008JCLI2508.1

Shaw PT, Csanady GT (1983) Self-Advection of Density Perturbations on a Sloping Continental Shelf. Journal of Physical Oceanography 13(5):769-782, doi:10.1175/15200485(1983)013\%3C0769:SAODPO\%3E2.0.CO;2

Smith DM, Cusack S, Colman AW, Folland CK, Harris GR, Murphy JM (2007) Improved Surface Temperature Prediction for the Coming Decade from a Global Climate Model. Science 317(5839):796-799, doi:10.1126/science.1139540

Smith RS, Gregory JM (2009) A study of the sensitivity of ocean overturning circulation and climate to freshwater input in different regions of the North Atlantic. Geophysical Research Letters 36(15):L15,701+, doi:10.1029/2009GL038607

Sutton R, Hodson D (2005) Atlantic ocean forcing of north american and european summer climate. Science 309:115-118

Sutton R, Hodson D (2007) Climate response to a multidecadal warming and cooling of the north atlantic ocean. J Climate 20(5):891-907

Sutton R, Jewson S, Rowell D (2000) The elements of climate variability in the tropical atlantic region. J Climate 13:3261-3284

Terray L, Cassou C (2002) Tropical atlantic sea surface temperature forcing of quasi-decadal climate variability over the north atlantic-europe region. J Climate 15(22):3170-3187

Trenberth KE, Caron JM (2001) Estimates of Meridional Atmosphere and Ocean Heat Transports. Journal of Climate 14(16):3433-3443, doi:10.1175/15200442(2001)014\%3C3433:EOMAAO\%3E2.0.CO;2

Vellinga M, Wu P (2004) Low-Latitude Freshwater Influence on Centennial Variability of the Atlantic Thermohaline Circulation. Journal of Climate 17(23):4498-4511

Vellinga M, Wood RA, Gregory JM (2002) Processes Governing the Recovery of a Perturbed Thermohaline Circulation in HadCM3. Journal of Climate 15(7):764-780, doi: 10.1175/1520-0442(2002)015\%3C0764:PGTROA\%3E2.0.CO;2

Wunsch C, Heimbach P (2006) Estimated Decadal Changes in the North Atlantic Meridional Overturning Circulation and Heat Flux 1993\&\#8211;2004. Journal of Physical Oceanography 36(11):2012-2024, doi:10.1175/JPO2957.1

Zhang D, Msadek R, McPhaden MJ, Delworth T (2011) Multidecadal variability of the North Brazil Current and its connection to the Atlantic meridional overturning circulation. Journal of Geophysical Research 116(C4):C04,012+, doi:10.1029/2010JC006812

Zhang R (2008) Coherent surface-subsurface fingerprint of the Atlantic meridional overturning circulation. Geophysical Research Letters 35:L20,705+, doi:10.1029/2008GL035463

Zhang Z, Kang SM, Held IM (2010) Sensitivity of Climate Change Induced by the Weakening of the Atlantic Meridional Overturning Circulation to Cloud Feedback. Journal of Climate 23:378-389 

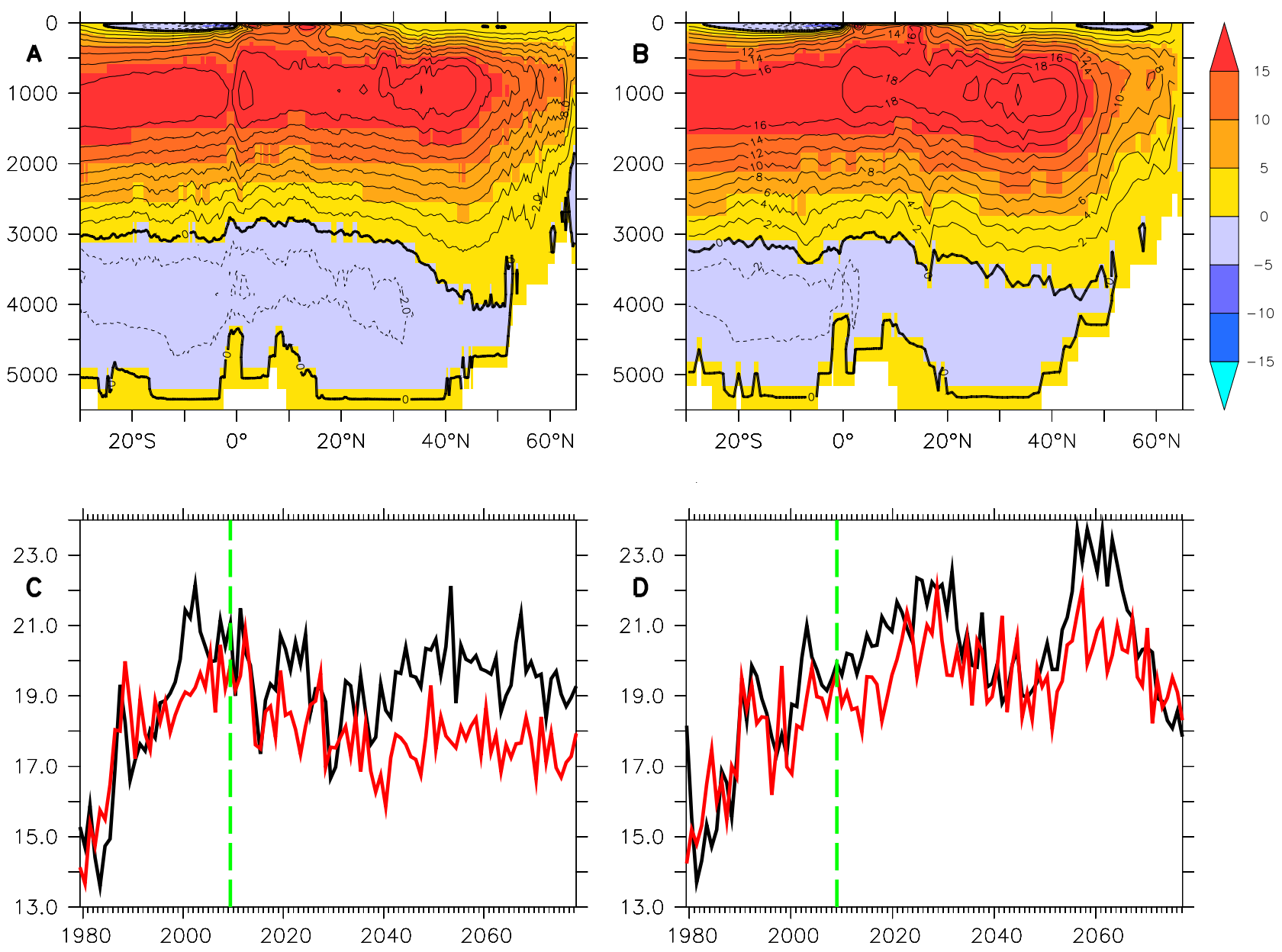

Fig. 1 Annual mean Atlantic meridional stream function (2009:2078, meridional velocity integrated from the ocean floor to a given depth) for A) HiGEM1.2 B) HadGEM1.2. C) Black line: MOC at 40N (meridional ocean velocity integrated across Atlantic basin and from ocean floor to $1000 \mathrm{~m}$ depth) in HiGEM1.2. Red line: Max Annual mean Atlantic meridional overturning streamfunction (i.e. panel A) at 26.7N in HiGEM1.2. Mean depth of max is $923 \mathrm{~m}$ for all years. D) as C, but for HadGEM1.2. Mean depth of max is $949 \mathrm{~m}$ for all years. All units are Sv $\left(10^{6} \mathrm{~m}^{3} / \mathrm{s}\right)$. Green dotted line denotes 2009 . All subsequent analysis is performed on data from 2009 to 2078 (unless otherwise stated) in order to exclude the initial rapid 30 year re-adjustment. 

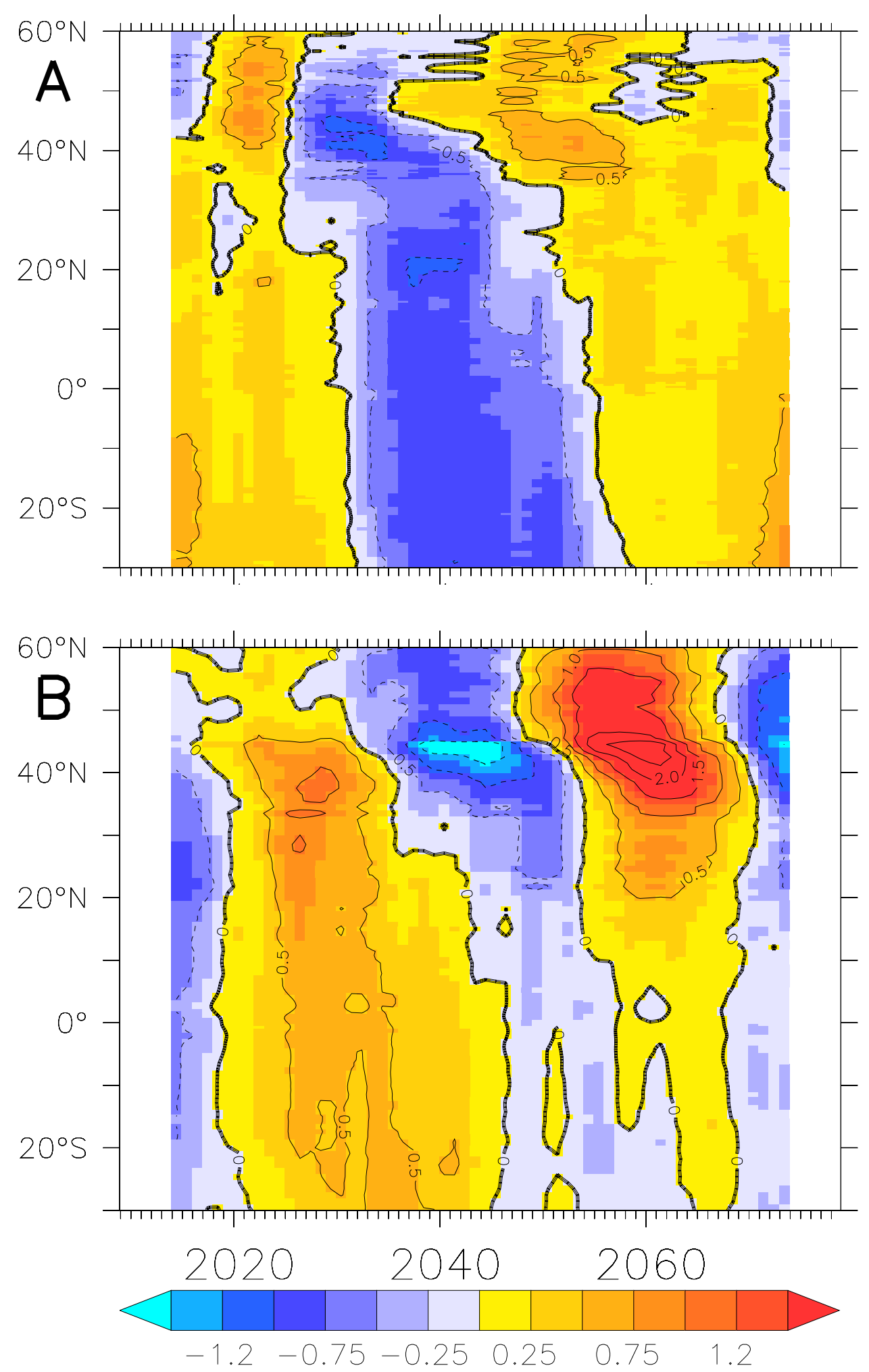

Fig. 2 A) Variation of annual mean HiGEM1.2 MOC (meridional ocean velocity integrated across Atlantic basin and from ocean floor to $1000 \mathrm{~m}$ depth) with latitude. Only the last 70 years of the 100 year integration were used in this analysis (2009:2078 see Fig. 1). Data from the remaining 70 years of has been detrended and then smoothed with a 10 year running mean time filter. B) as A, but for HadGEM1.2. Units are Sv. 


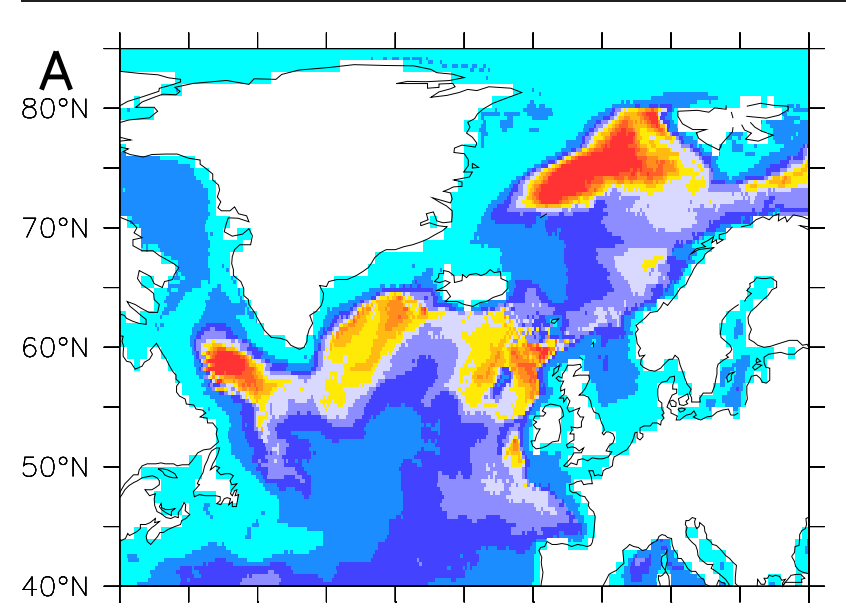

B
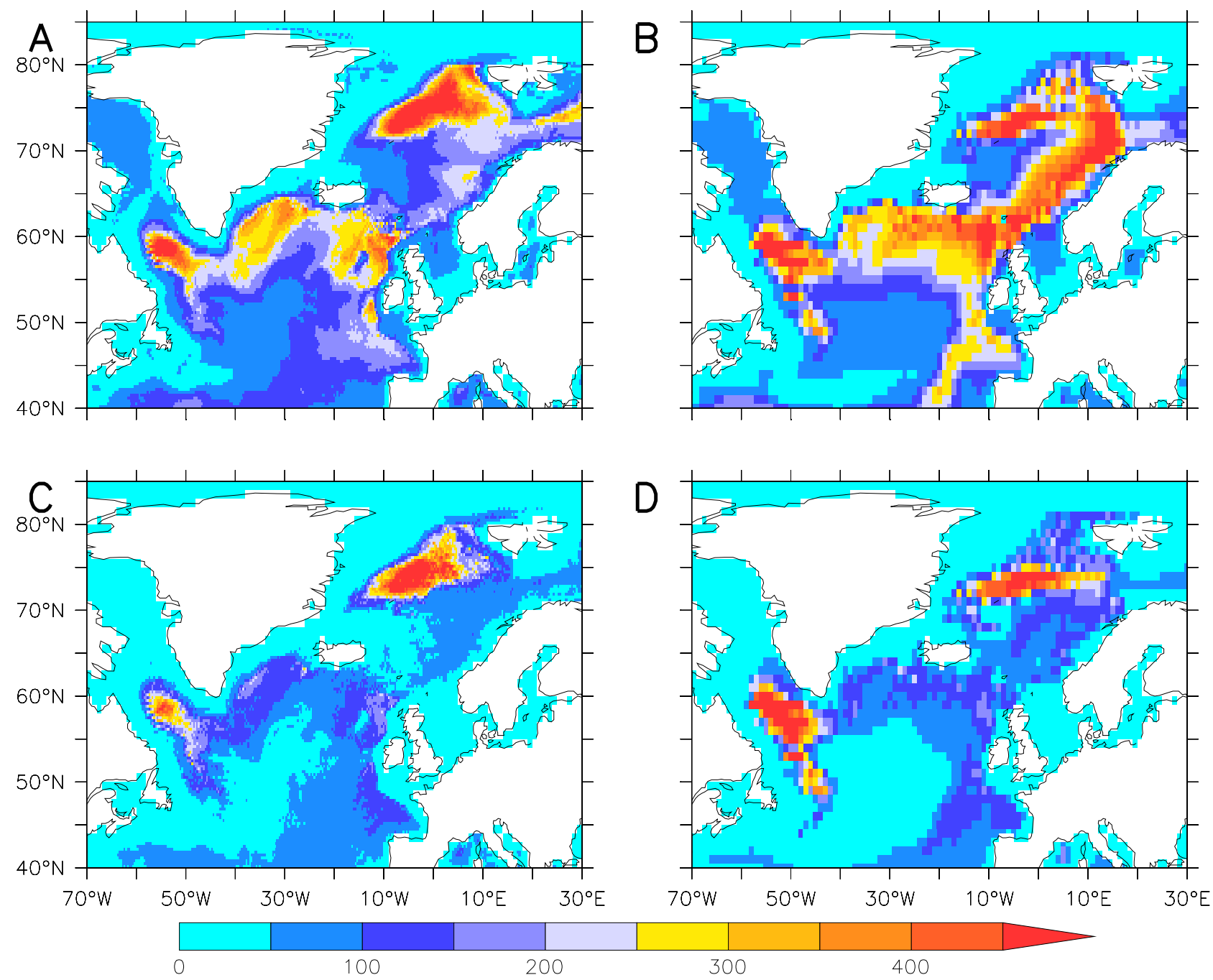

D

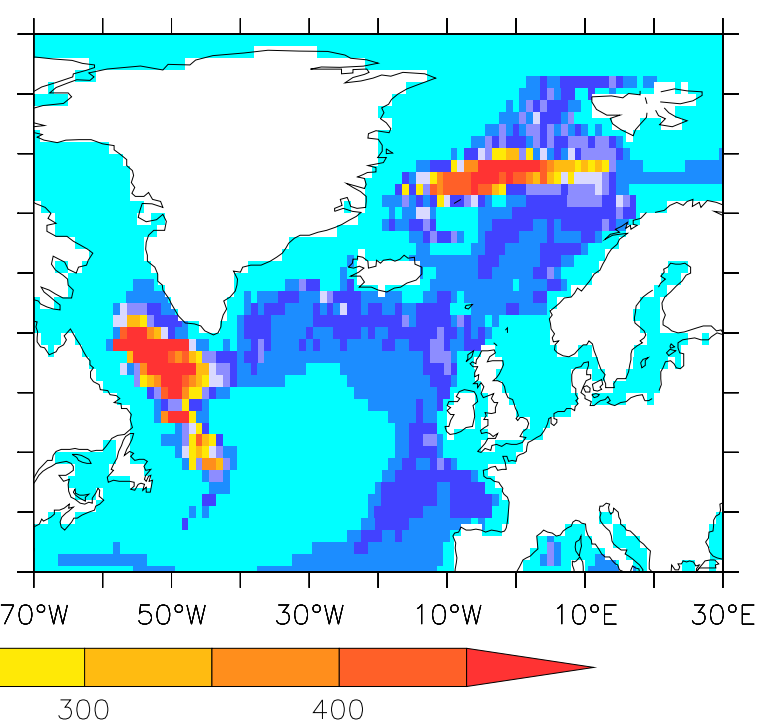

Fig. 3 A) HiGEM1.2 March mean ocean mixed layer depth (2009:2078). B) As A for HadGEM1.2. C) HiGEM1.2 March standard deviation of ocean mixed layer depth (2009:2078). D) As C for HadGEM1.2. Units are $\mathrm{m}$. 

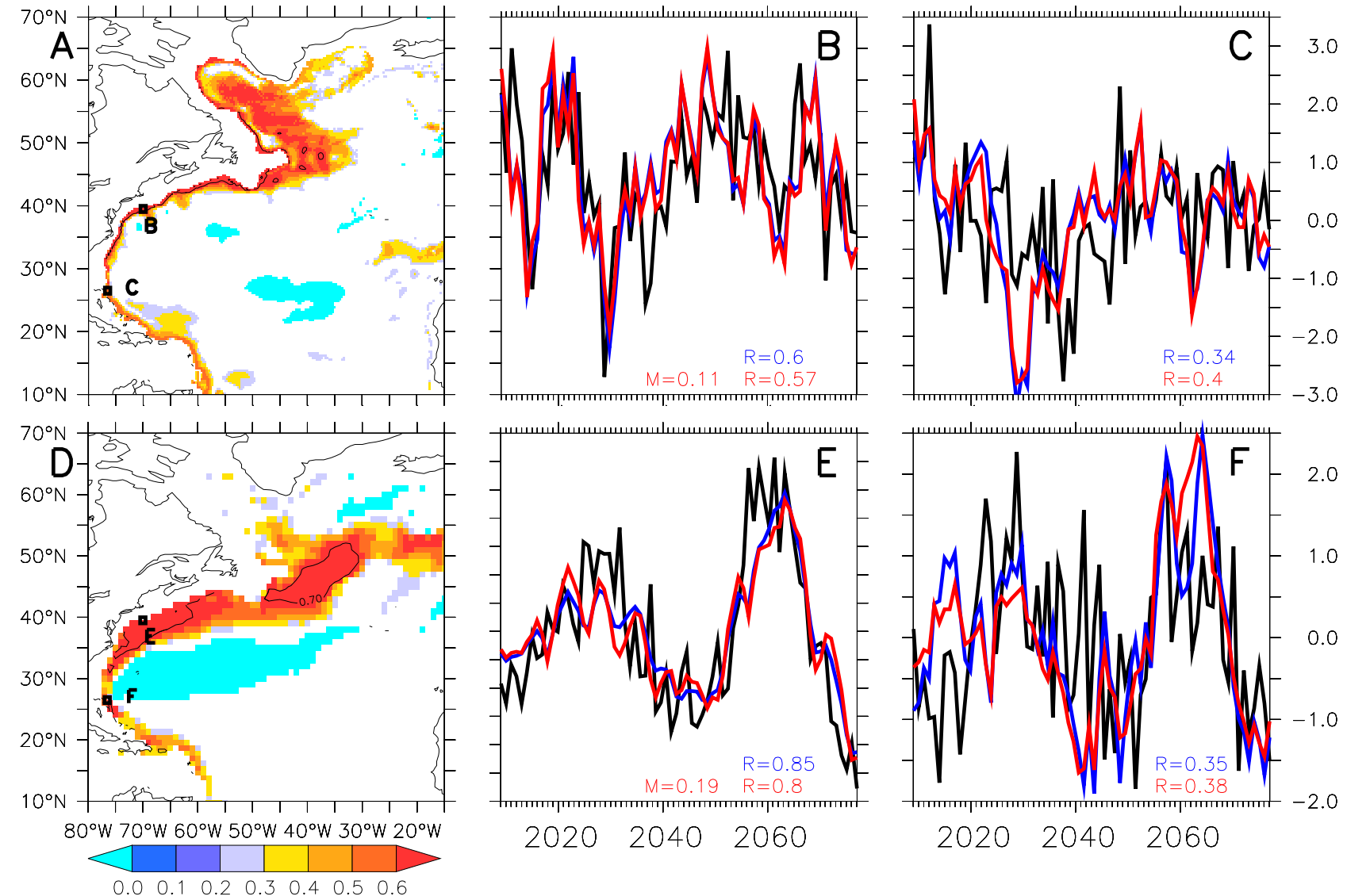

Fig. 4 A) HiGEM1.2 integrated Ocean density (1500-3000m) correlated with integrated density index at point B (MOC* see panel B: red line). Correlation of 0.7 is contoured. B) Black line: detrended MOC index (as Fig 1C) at 40N. Red Line: index of Detrended (years 31-100), box-averaged (70.5:69.5W,39:40N, box labelled B, in panel A, MOC*) ocean density, integrated between 1500 and $3000 \mathrm{~m}$. Blue line: as Red line but for double integrated ocean density, as described in equation C) Black line: detrended MOC index (as Fig 1C) at 26.7N. Red Line: index of Detrended (years 31-100), box-averaged (77:76W,26:27N, box labelled C, in panel A) ocean density, integrated between 1500 and 3000m. Blue line: as Red line but for double integrated ocean density, as described in equation All indices in B and C have been standardized before plotting. E-F) As A-C, but for HadGEM1.2. Correlation coefficients between MOC (black) and Integrated Density (red) indices are given in red in the bottom right hand corner of each panel.Correlation coefficients $(\mathbf{R})$ between MOC (black) and Doubly Integrated Density (blue) indices are given in blue in the bottom right hand corner of each panel. Regression coefficients (M) between MOC* (red) and MOC (black) (before standardization) are also given in the bottom right hand corner of panels B and $\mathrm{E}$ (Units $\mathrm{Sv} /\left(\mathrm{kg} / \mathrm{m}^{2}\right)$ ). 


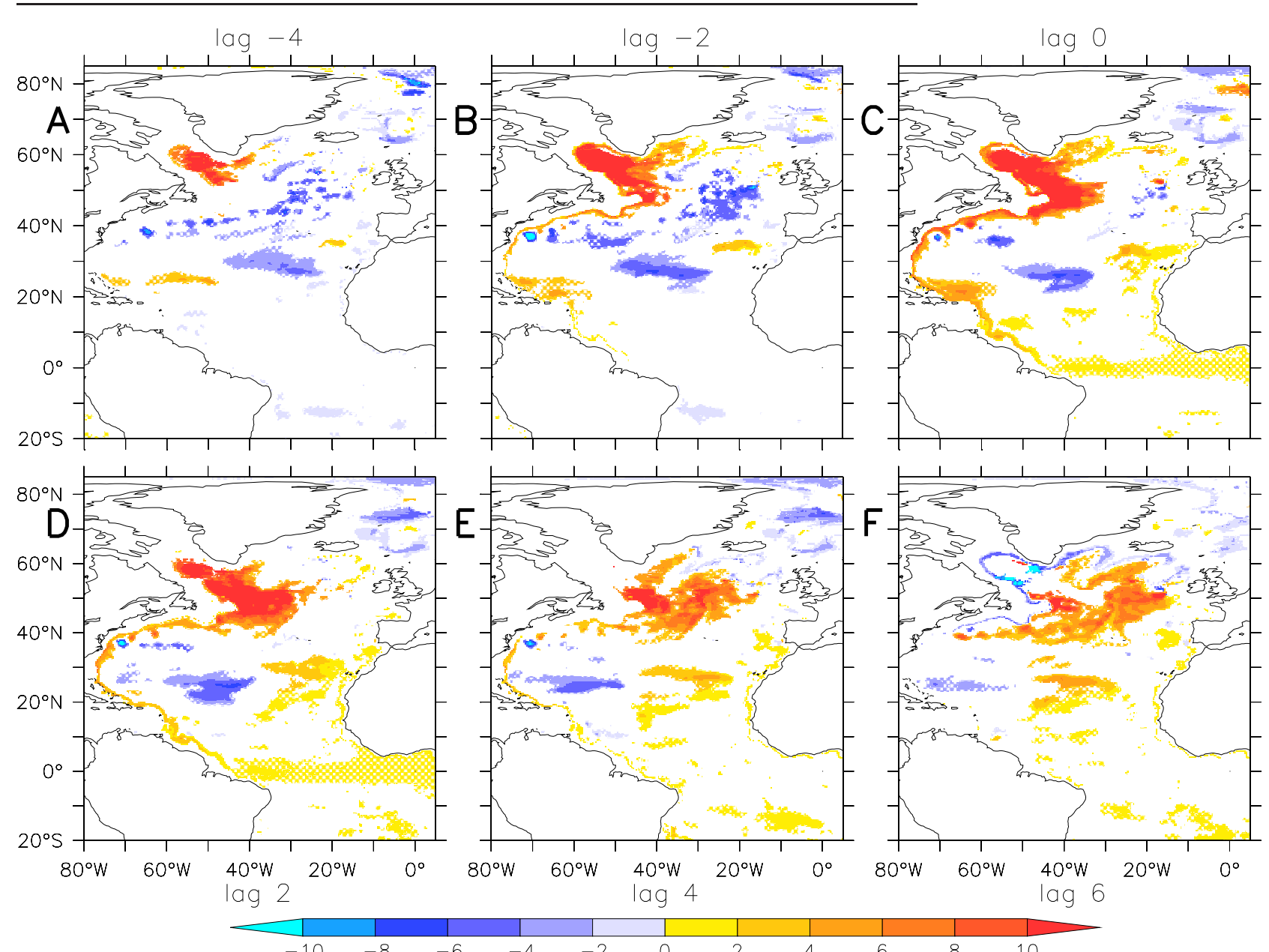

Fig. 5 Annual mean HiGEM1.2 ocean density integrated between $1500 \mathrm{~m}$ and $3000 \mathrm{~m}$ then lag regressed onto $M C^{*}$ - a detrended MOC-proxy index at 40N (see Fig. 4). The ocean Lags the MOC* index for positive lags. Only the last 70 years of the 100 year integration were used in this analysis (2009-2078) (see Figure 1). Here we have multiplied $\mathrm{MOC}^{*}$ by the regression value from Figure $4 \mathrm{~b}\left(\mathbf{M}=0.11 \mathrm{~Sv} /\left(\mathrm{kg} \mathrm{m}^{-2}\right)\right)$ beforehand. Hence the units are $\mathrm{kg} \mathrm{m}^{-2} / \mathrm{Sv}$. Regions where the regression is significant $(p<0.05)$ are solid shaded. Regions where $(0.05 \leq p<0.10)$ are stippled shading. 


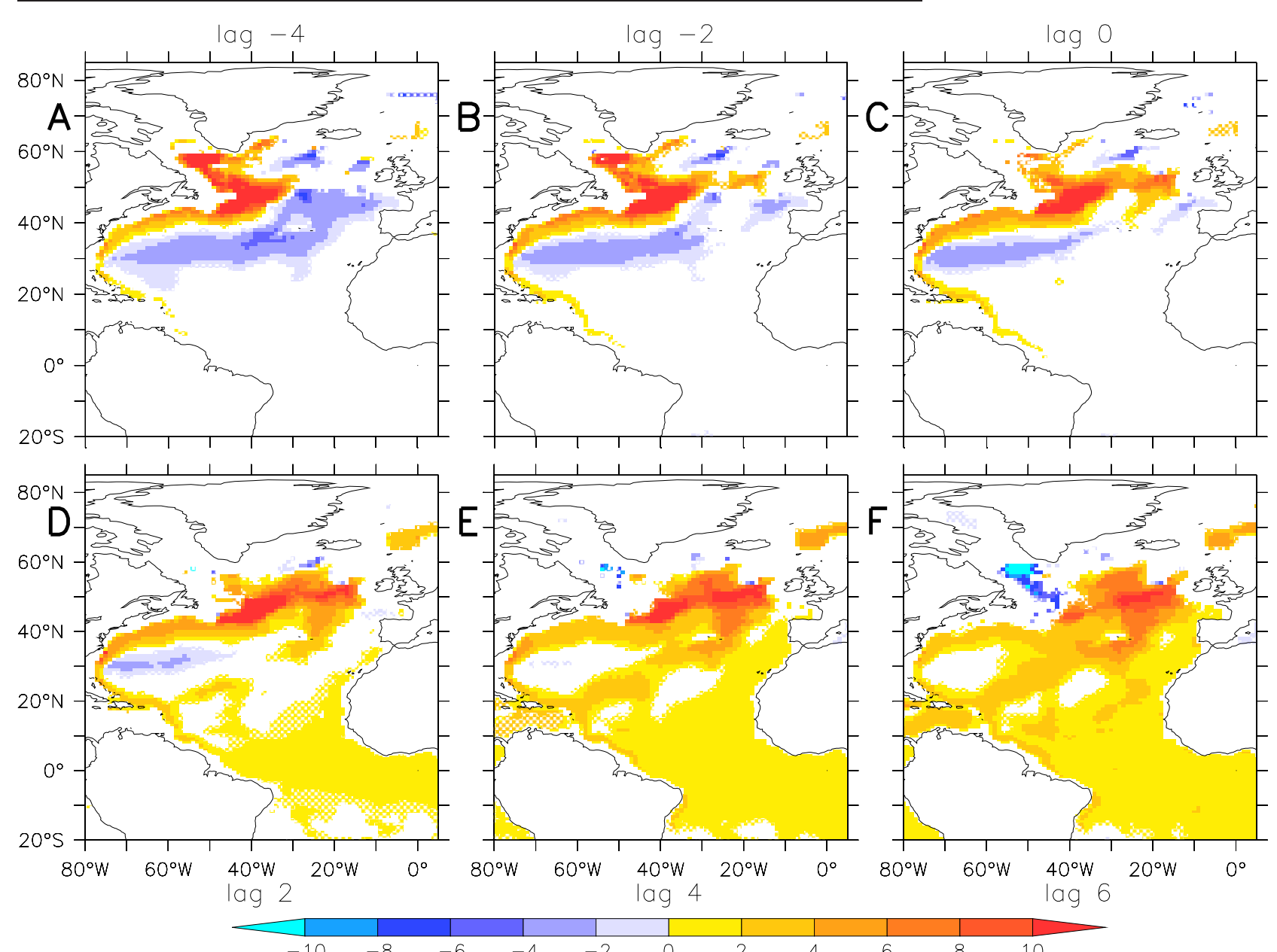

Fig. 6 As Figure 5 but for HadGEM1.2. Here we have multiplied MOC* ${ }^{*}$ by the regression value from Figure $4 \mathrm{~b}\left(\mathbf{M}=0.18 \mathrm{~Sv} /\left(\mathrm{kg} \mathrm{m}^{-2}\right)\right)$ beforehand. Hence the units are $\mathrm{kg} \mathrm{m}^{-2} / \mathrm{Sv}$. 


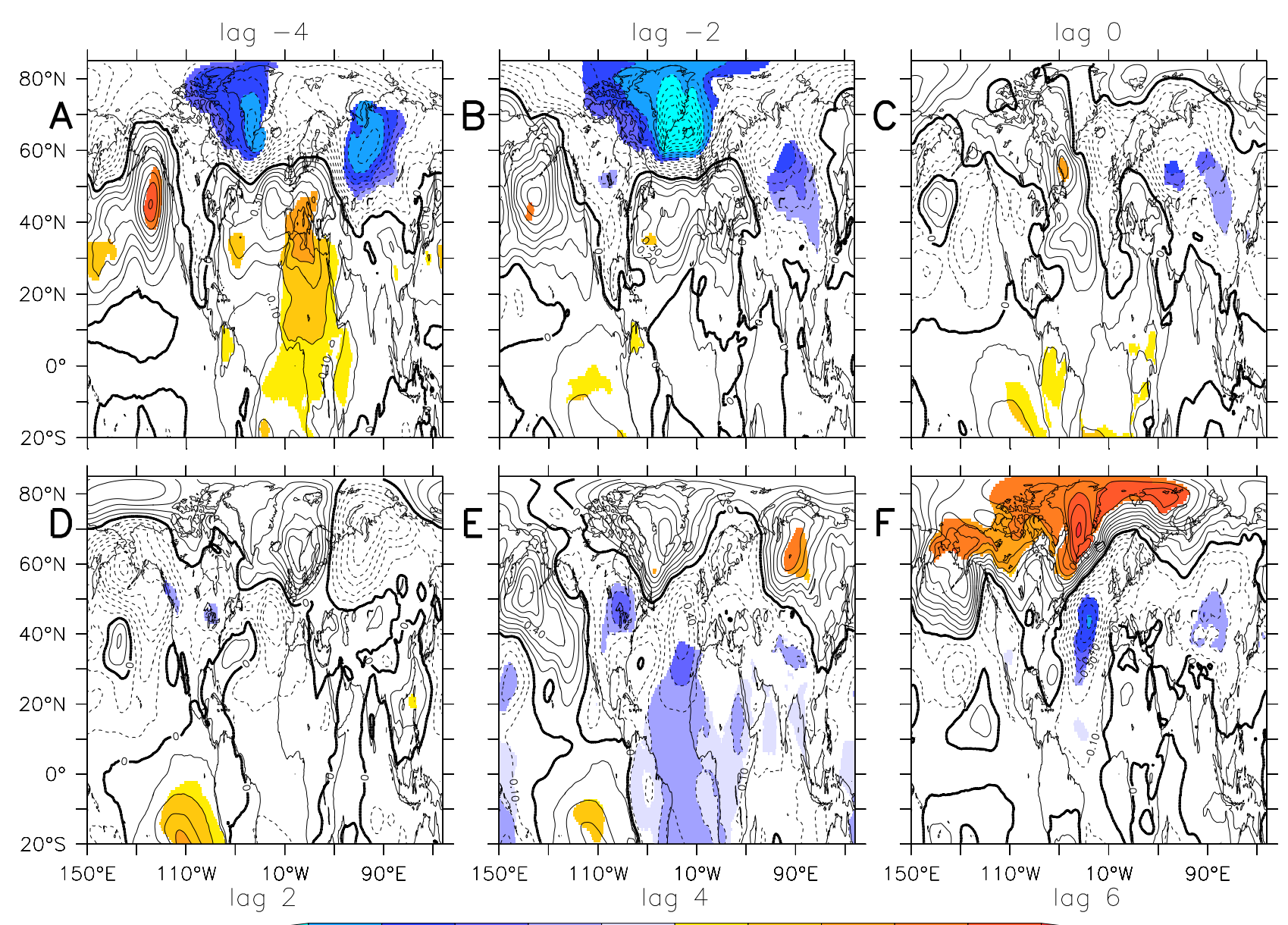

Fig. 7 Annual mean Mean Sea Level Pressure (MSLP) regressed on MOC*, the detrended boundary density index at 40N defined in Figure 4. MSLP field lags boundary index (Hence MOC) for positive lags. As before we have multiplied $\mathrm{MOC}^{*}$ by $0.11\left(\mathrm{~Sv} /\left(\mathrm{kg} \mathrm{m}^{-2}\right)\right)$ beforehand. Hence the units are $\mathrm{hPa} / \mathrm{Sv}$. Regions where the regression is significant $(p<0.05)$ are solid shaded. 

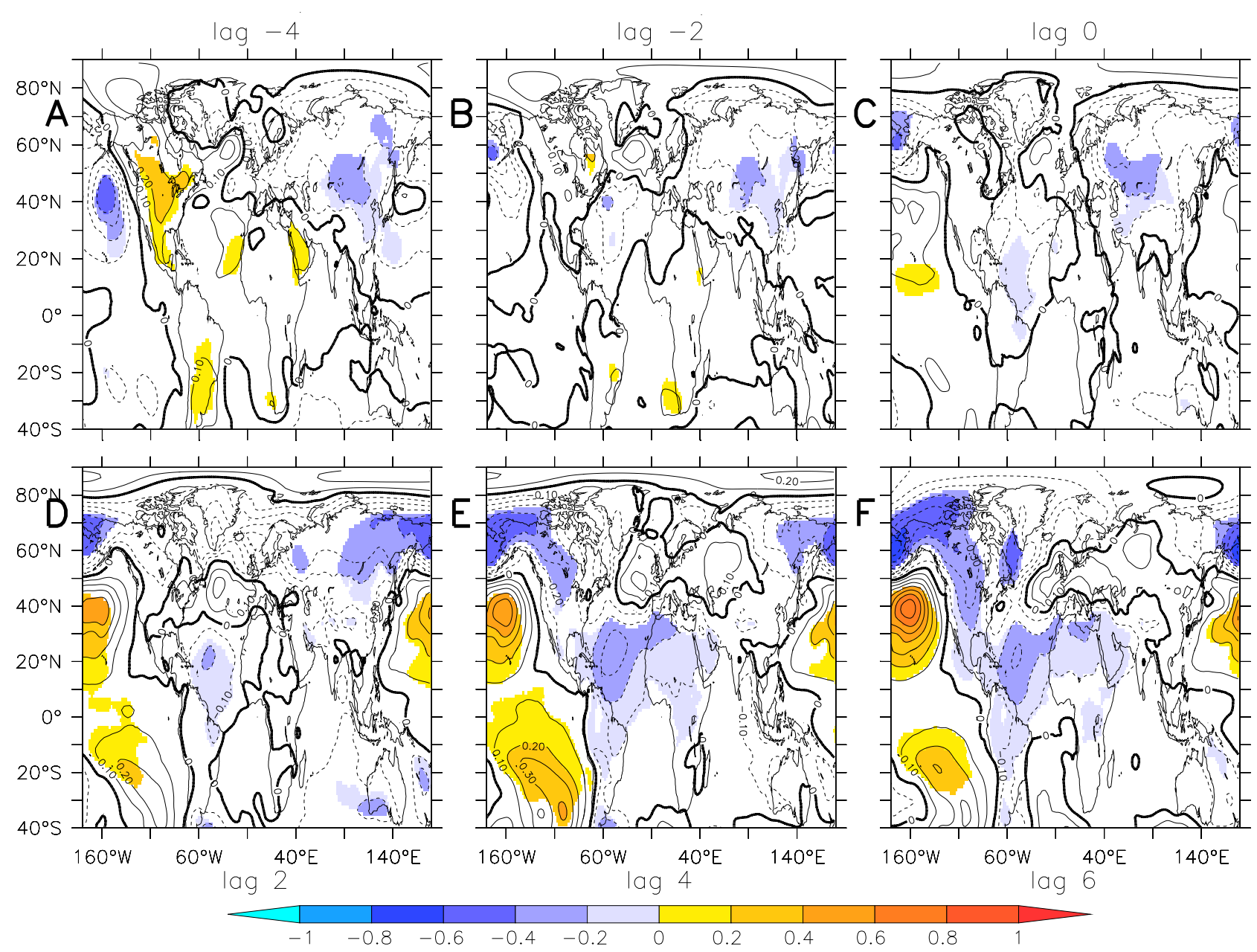

Fig. 8 As Figure 7 but for HadGEM1.2. As before we have multiplied MOC* by $0.18\left(\mathrm{~Sv} /\left(\mathrm{kg} \mathrm{m}^{-2}\right)\right)$ beforehand. Hence the units are $\mathrm{hPa} / \mathrm{Sv}$. 


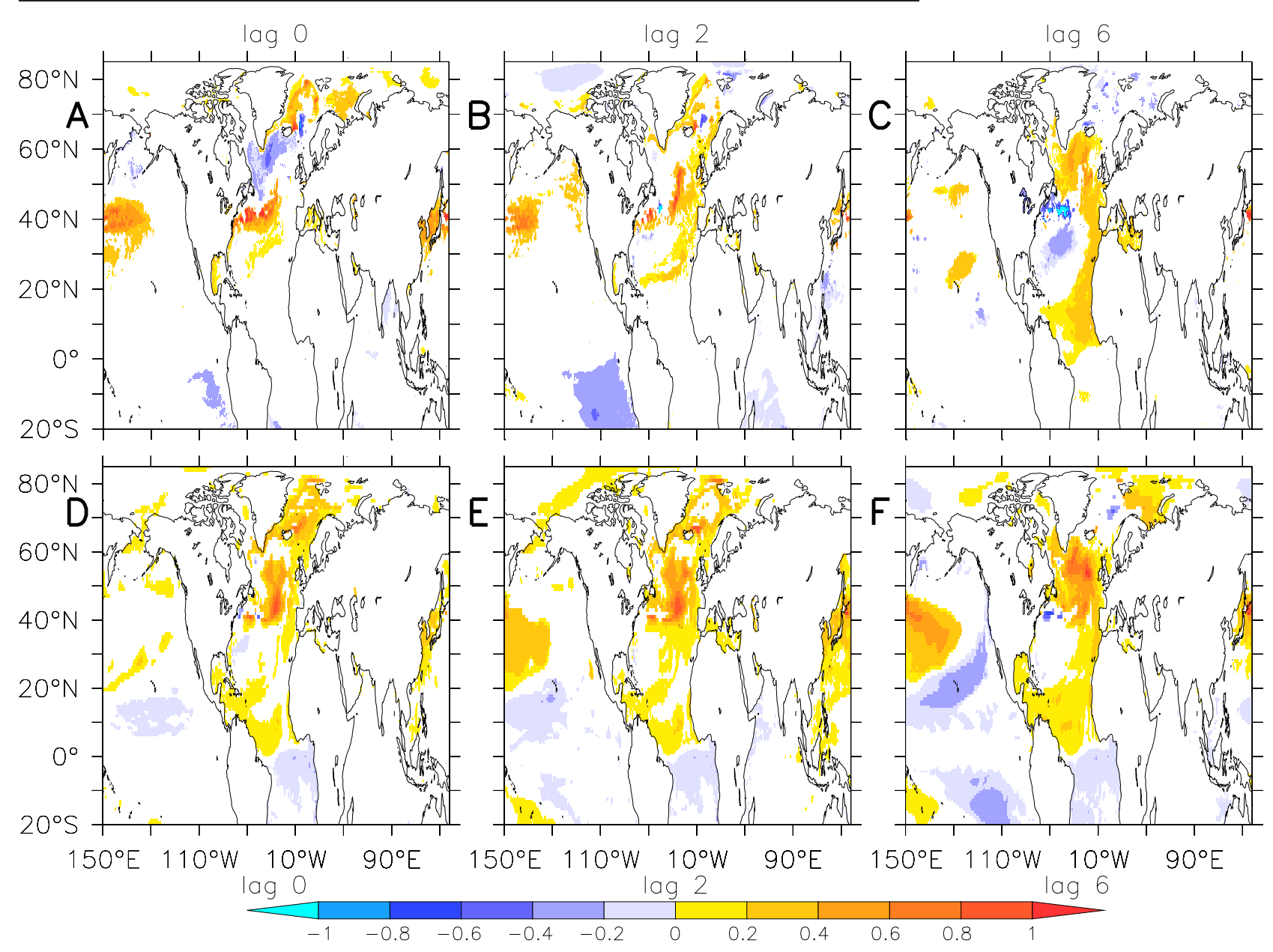

Fig. 9 As Figure 7 but for Sea Surface Temperatures (SSTs). A-C) HiGEM1.2. D-F) HadGEM1.2. MOC* has been scaled appropriately as before. Hence units are K/Sv. 


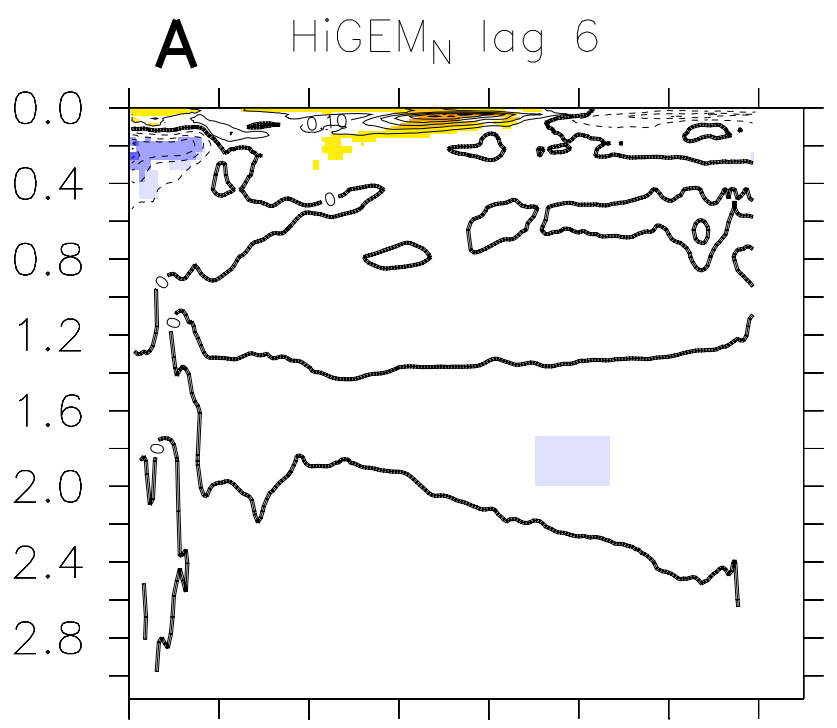

B $\operatorname{HadGEM}_{N} \operatorname{lag} 6$

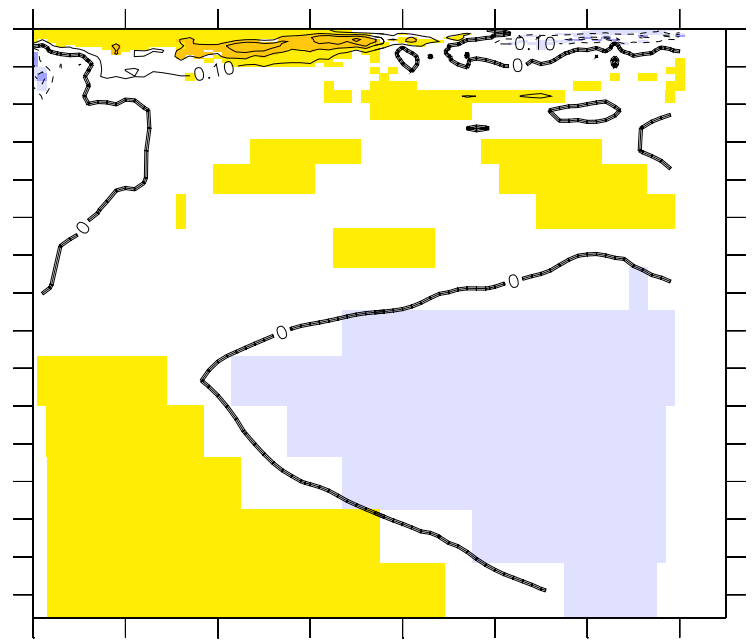

C $\operatorname{HadGEM}_{N} \operatorname{lag} 6$

D HadGEMS $_{S} \operatorname{lag} 6$
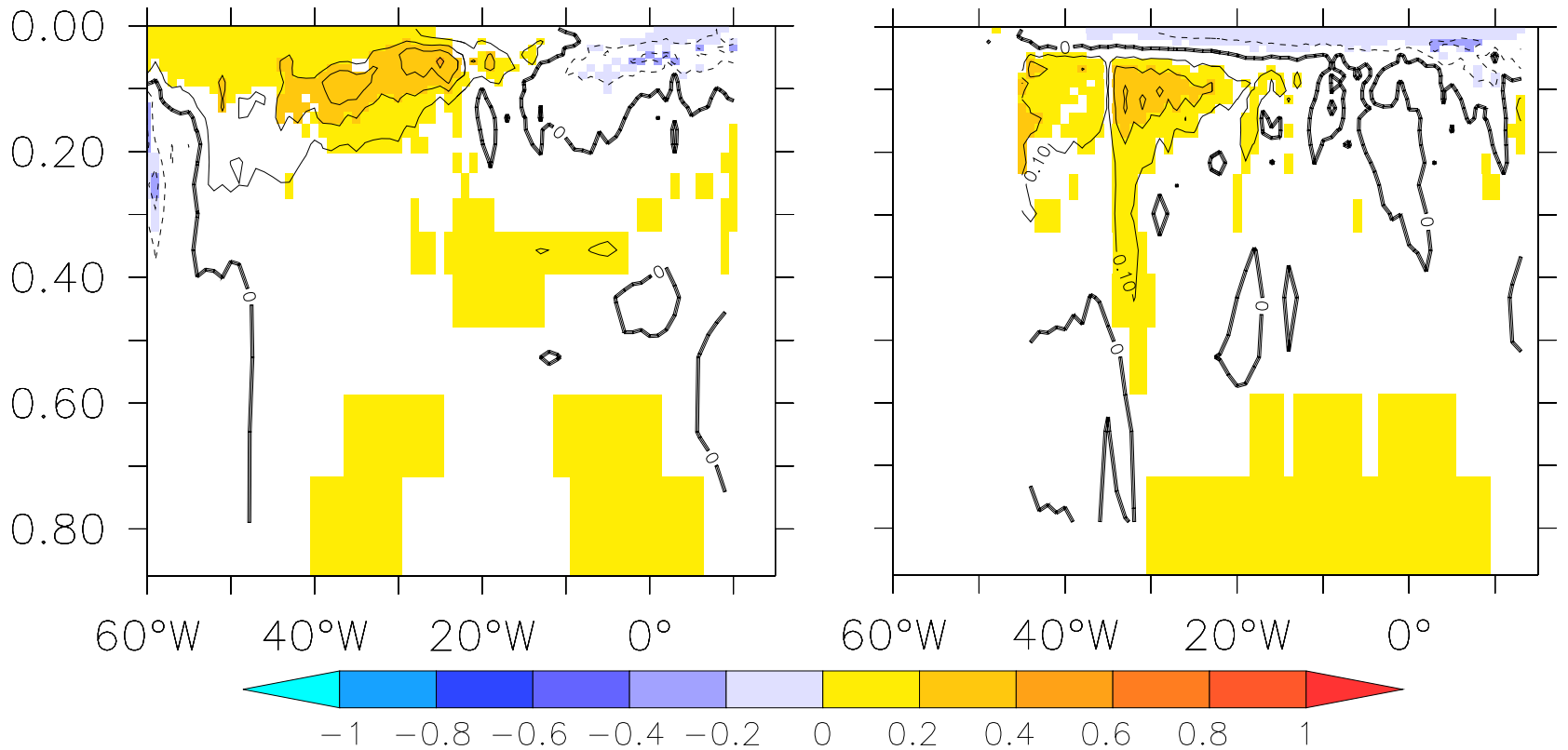
lag regressed on the detrended boundary density index at 40N (B in Fig 4a, defined as MOC* in text). Plot shows ocean temperatures six years after an increase in $\mathrm{MOC}^{*}$. $\mathrm{MOC}^{*}$ has been scaled appropriately as before. Hence units are K/Sv. b) as a) but for HadGEM1.2. c) An expanded version of b) to show the upper ocean warming. d) as c) but for 0:10S. Units on vertical axes are $\mathrm{km}$. 


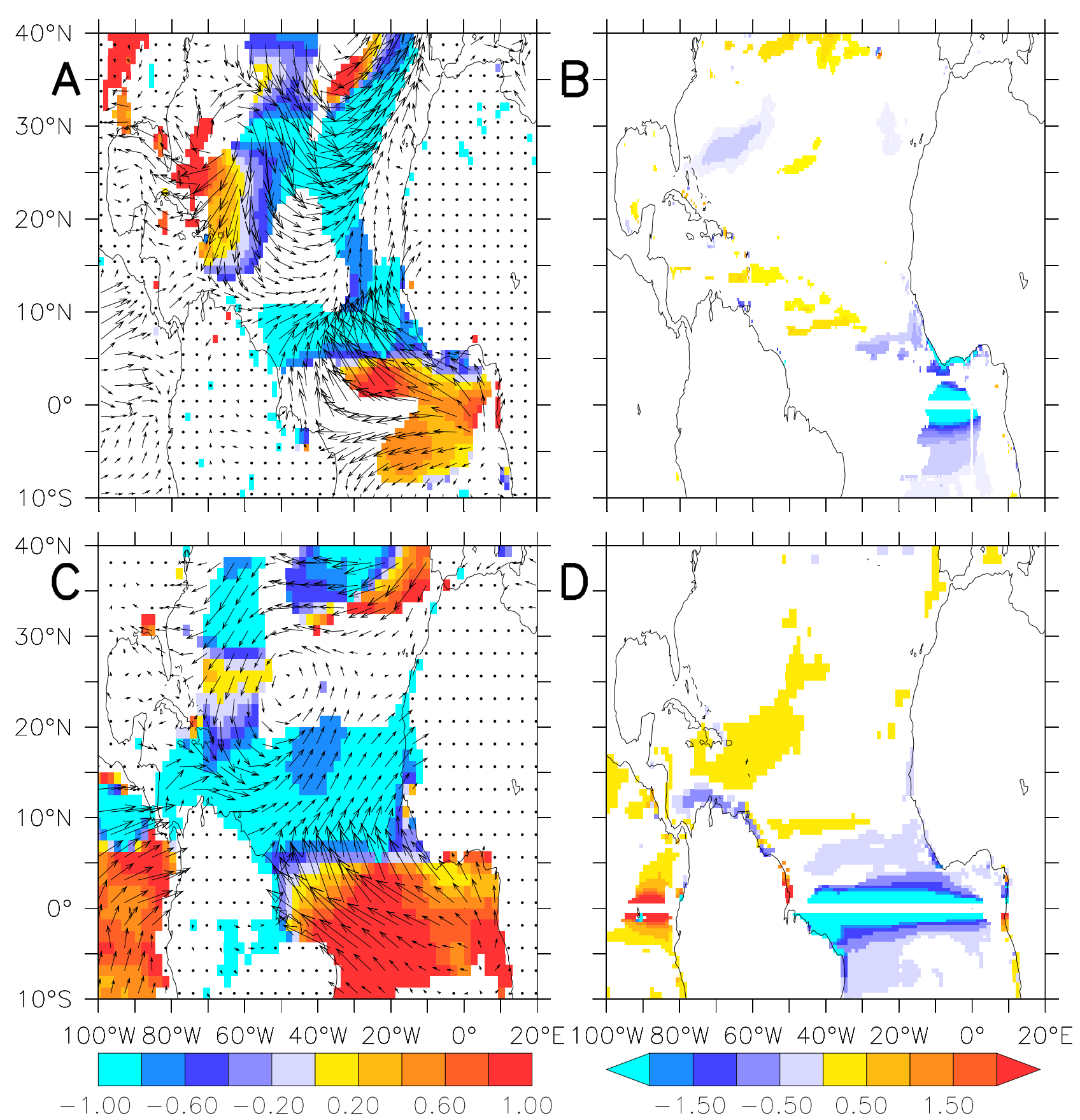

Fig. 11 Surface Winds and Ekman Pumping. a) HiGEM1.2 Surface winds lag regressed onto the detrended boundary density index $\left(\mathrm{MOC}^{*}\right)$ at $40 \mathrm{~N}$ at Lag 6 . Plot shows surface wind anomalies six years after an increase in $\mathrm{MOC}^{*}$. The shading shows the scalar product of the normalized wind anomalies with the normalized mean climatological wind at a grid point (i.e the cosine of the angle between these two vectors). Hence regions where the anomalous wind weakens (strengthens) the mean winds, leading to reduced (enhanced) surface cooling, are shaded blue (red). Only regions where the magnitude of the regression is significant $(p<0.05)$ are shaded. b) HiGEM1.2 Ekman pumping, computed from surface wind stress curl, lag regressed onto the detrended boundary density index $\left(\mathrm{MOC}^{*}\right)$ at $40 \mathrm{~N}$ at Lag 6 . Regions where the regression is significant $(p<0.05)$ are shaded. The region between $0.5 \mathrm{~S}$ and $0.5 \mathrm{~N}$ is masked out, because the expression for calculating Ekman pumping diverges near the equator. $\mathrm{MOC}^{*}$ has been scaled appropriately as before. Hence, units are $10^{-6} \mathrm{~ms}^{-1} / \mathrm{Sv}$ c) as a) but for HadGEM1.2. d) as b) but for HadGEM1.2. 


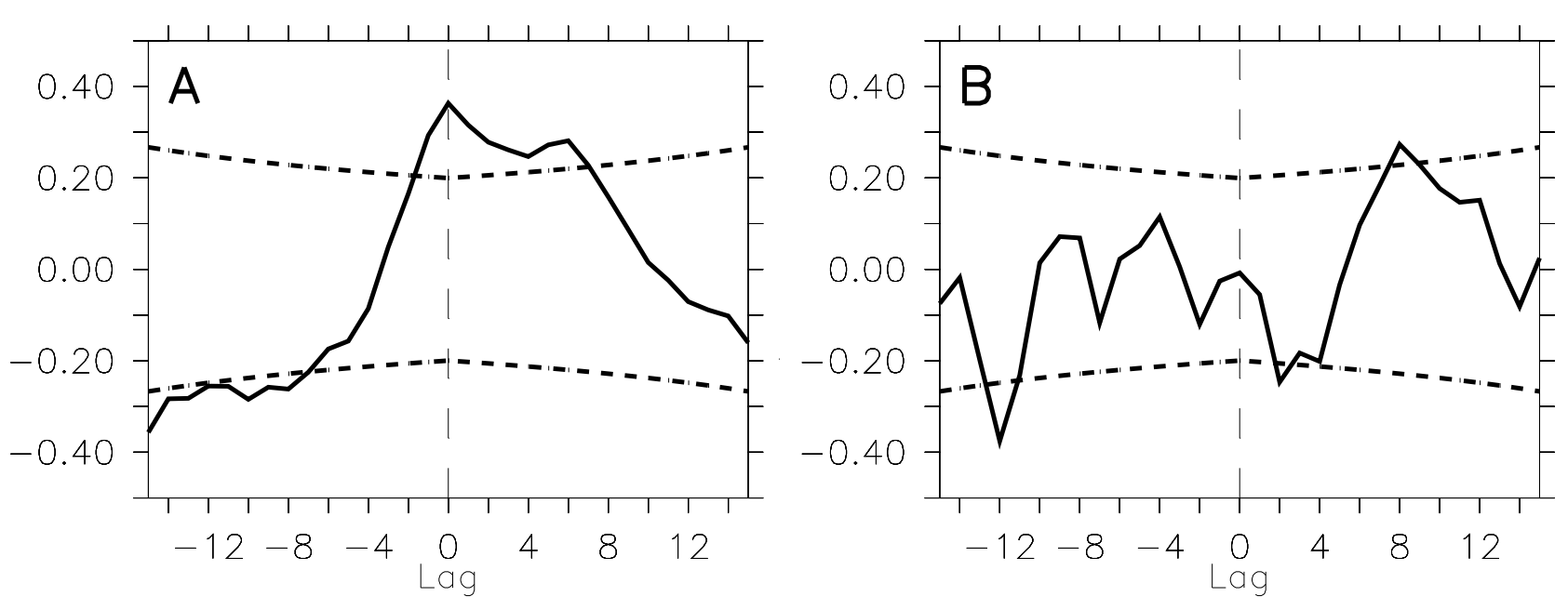

Fig. 12 A) Lag correlation of an index of the North Brazil Current (NBC) and MOC* in HadGEM1.2. MOC* $^{*}$ leads for positive lags. Dotted lines indicate significant correlation level $(p<0.05)$. B) as A) but for HiGEM1.2. 